$1-1-2013$

\title{
Physiological And Psychological Responses To 911 Emergency Tapes
}

Jackie Hammelman

jackie.hammelman@gmail.com

This document is a product of extensive research conducted at the Nova Southeastern University College of Psychology. For more information on research and degree programs at the NSU College of Psychology, please click here.

Follow this and additional works at: https://nsuworks.nova.edu/cps_stuetd

Part of the Psychology Commons

\section{Share Feedback About This Item}

\section{NSUWorks Citation}

Hammelman, J. (2013). Physiological And Psychological Responses To 911 Emergency Tapes. .

Available at: https://nsuworks.nova.edu/cps_stuetd/99

This Dissertation is brought to you by the College of Psychology at NSUWorks. It has been accepted for inclusion in College of Psychology Theses and Dissertations by an authorized administrator of NSUWorks. For more information, please contact nsuworks@nova.edu. 
PHYSIOLOGICAL AND PSYCHOLOGICAL RESPONSES TO 911

\title{
EMERGENCY TAPES
}

\section{By}

\author{
Jackie D. Hammelman
}

\author{
A Dissertation Presented to the School of Psychology \\ of Nova Southeastern University \\ in Partial Fulfillment of the Requirements \\ for the Degree of Doctor of Philosophy
}

NOVA SOUTHEASTERN UNIVERSITY

2012 


\section{APPROVAL PAGE}

This dissertation was submitted by Jackie Hammelman under the direction of Dr. Stephen Campbell of the dissertation committee listed below. It was submitted to the School of Psychology and approved in partial fulfillment of the requirements for the degree of Doctor of Philosophy in Clinical Psychology at Nova Southeastern University.

Approved:

Date of Defense

Stephen Campbell, Ph.D., Chairperson

Edward Simco, Ph.D.

Alexandru Cuc, Ph.D.

Date of Final Approval

Stephen Campbell, Ph.D., Chairperson 


\section{ACKNOWLEDGEMENTS}

It is my pleasure to thank those who made this research possible, first and foremost members of my dissertation committee, and specifically Dr. Stephen Campbell for his continued guidance in all my academic, professional, and humanitarian pursuits.

Operating under his guidance has made me a better professional and human being. I also would like to make a special reference to Benjamin Greenberg and Dr. Jeffrey Kibler for so graciously allowing me to utilize the biofeedback lab and offering their training with the BioTrace system. 


\section{TABLE OF CONTENTS}

LIST OF TABLES

LIST OF FIGURES vii

$\begin{array}{ll}\text { ABSTRACT } & 8\end{array}$

CHAPTER I: STATEMENT OF THE PROBLEM 9

CHAPTER II: LITERATURE REVIEW 10

$\begin{array}{ll}\text { Physiology of Stress and Trauma } & 10\end{array}$

$\begin{array}{ll}\text { General Adaptation Syndrome } & 12\end{array}$

$\begin{array}{ll}\text { Secondary Trauma } & 14\end{array}$

Impact of Exposure to Trauma in Media 23

Purpose of the Study $\quad 32$

$\begin{array}{ll}\text { Hypotheses } & 32\end{array}$

CHAPTER III: METHOD 33

$\begin{array}{ll}\text { Subjects } & 33\end{array}$

Inclusion and Exclusion Criteria 33

$\begin{array}{ll}\text { Measures } & 34\end{array}$

$\begin{array}{ll}\text { Procedures } & 36\end{array}$

$\begin{array}{ll}\text { Consent } & 37\end{array}$

CHAPTER IV: RESULTS 39

Post Hoc Analyses 43

CHAPTER V: DISCUSSION

Limitations of the Study 
Findings Relative to Previous Research $\quad 56$

Implications for Practice and Future Research 59

$\begin{array}{ll}\text { REFERENCES } & 62\end{array}$

APPENDICES

$\begin{array}{ll}\text { A. Profile of Mood States (POMS) } & 74\end{array}$

B. NEO Personality Inventory Revised Edition ( NEO-PI-R) 76

C. Multi-Dimensional Emotional Empathy Scale (EES) 83

D. PTSD Checklist Civilian Version (PTSD-C) 84 


\section{LIST OF TABLES}

Table 1: Descriptive Statistics for Mood State as Measured by the POMS and

Arousal

Table 2: Correlations Between Arousal in the 911 Emergency Call Condition and

Mood State

Table 3: Semipartial Correlations Between Arousal and Personality Characteristics

Table 4: Correlations Between Arousal and PTSD-C Score

Table 5: Statistics for Baseline 1 and Baseline 2 on Arousal States

Table 6: Correlations Between Empathy and Mood State

Table 7: Pearson Correlations Between Empathy and Personality Characteristics

Table 8: Pearson Correlations Between Age and Arousal in the 911 Emergency Call

Condition and Baseline

Table 9: Pearson Correlations Between Age Personality Characteristics, and Empathy

Table 10: Pearson Correlations Between Age, Mood, and PTSD Baseline

Table 11: Statistics for Mood State Along Gender

Table 12: Statistics for Arousal at Baseline and 911 Emergency Phone Call Condition Along Gender 


\section{LIST OF FIGURES}

$\begin{array}{ll}\text { Figure 1: GSR Across Conditions } & 71\end{array}$

Figure 2: Respiration Rate Across Conditions 72

Figure 3: Heart Rate Across Experimental Conditions $\quad 73$ 


\begin{abstract}
The news has become a central part of daily culture in the United States and provides up to date information regarding a vast array of topics from weather to war. A specific aspect of the news, emergency 911 tapes, and their influence on viewers' physiological and psychological health was investigated. Research regarding the relationship between physiological arousal and exposure to brief traumatic stimuli, as well as research addressing the development of pathological psychiatric symptoms are discussed in the literature review. This study examined the relationship between exposure to 911 emergency tapes, physiological arousal, and symptoms of psychopathology while considering the influence of trait personality characteristics and state mood. Results identified significant differences in physiological response to the 911 emergency condition compared to news reports. No significant differences were identified between mood state and arousal except in the instance of respiration rate and negative mood; those with higher scores on negative mood displayed higher levels of respiration. Personality factors and empathy were examined for their predictive value on level of arousal, and yielded insignificant results. Finally, baseline level of PTSD was not significantly correlated with arousal in the 911 condition, except in terms of respiration rate. Future research is required to better understand the arousal as a result of exposure to such media, and the associated psychological and physiological health implications.
\end{abstract}




\section{Chapter I}

\section{Statement of the Problem}

The average American who lives to be 65 spends approximately nine years watching television (Nielsen Media Research Company, 2010). According to the United States Department of Labor (2010) television watching was the most common form of leisure activity, with the average American viewing approximately 2.8 hours every day. The average number of violent acts observed by the age of 18 is approximately 200,000, with $53.8 \%$ being related to crime, war, or disaster (Nielsen Media Research Company, 2010). When questioned about the influence of viewing violent acts, $79 \%$ of Americans believe exposure leads to later acts of violence (Nielsen, 2010). The American Psychiatric Association, American Medical Association, American Heart Association, and numerous other professional organizations have recently taken action due to concerns over the negative impact television has on mental and physical health. These organizations have become the official sponsors of National TV Turnoff Week (Boyse, 2010) in an effort to reduce associated health risks of viewing violence on television. Thousands of studies have investigated the negative impact of the media considering exposure to violent or aggressive acts, and have collectively concluded that exposure, particularly in childhood, not only leads to later violent behavior, but also reduces helping behavior (Huesmann, Moie-Titus, Podolski, \& Eron, 2003; Johnson, Cohen, Smalies, Kasen, \& Brooks, 2002; Bushman \& Anderson, 2009).

Although there has been research investigating the effects of trauma or violence in different forms of media, (i.e., video games or movies) there has been little research 
addressing the impact of exposure to genuine human violence or traumatic experience through the news. This is an area that deserves further attention given the level of exposure on a daily basis and across one's lifespan. Additionally, this area is deserving of attention when considering repeated exposure to traumatic stimuli may have a detrimental impact on both physiological and psychological health. If findings are validated, and a relationship is established between exposure to such media and measure of psychological mood and physical arousal, the news may be driven to remove this aspect of their reports, which intrinsically offers no novel information to the reported story. Finally, investigation of personality factors and mood states may help to identify if certain people are at higher risk to experience more elevated distress symptoms as observed by an increase in physical arousal.

\section{Chapter II}

\section{Review of Literature}

\section{Physiology of Stress and Trauma}

Fight or Flight. The manner in which the human body reacts on a physiological level commonly referred to as stress was extensively examined and documented by Walter Cannon. Cannon is best known for his research surrounding the fight or fight response (Cannon, 1915) common to all humans when confronted with a threat, such as exposure to threatening stimuli. Cannon identified the sympathetic nervous system (SNS) activates in a predictable manner in the face of a threat to prepare the individual for fighting and holding their ground, or fleeing from the situation. Biological functions that show expression of this response include heart rate, blood pressure, perspiration, 
respiration, temperature, and vision. As humans we biologically react the same way when in danger: the respiratory system increases activity, blood pressure and body temperature decreases, our pupils dilate, and our amount of sweat increases.

In order to measure how the human body reacts to such fight or flight situations, (i.e., traumatic stimuli) historically biofeedback machinery has been utilized to track physiological differences related to SNS function. For instance, changes in galvanic skin response (GSR), electroencephalography (EEG), and electromyography (EMG) have been monitored to measure the impact of emotional subliminal messages in media advertisements (Ohme, Reykowska, Wiener, \& Choromanska, 2009). Forty-five nonpsychiatric female participants between the age of 25 -35 were shown two experimental advertisements along with ten control advertisements that were free from an emotionally provocative image. Significant differences were observed in EEG and EMG responses across the two conditions with more brain activation in the emotional lobes and higher facial activity in the subliminal condition. Independent t-tests also identified a significantly higher response according to GSR in the more emotional advertisement. Overall, analysis revealed a clear correlation between changes in GSR and emotionally evoking stimuli that is consistent with the fight or flight reaction, even when the stimuli was processed out of conscious awareness.

The stress specific response to a threat has additionally been documented according to changes in skin temperature and heart rate (Baker \& Taylor, 1954). Fiftytwo psychology students from Purdue University were subjected to two emotionprovoking situations, one including an electrical spark and a second condition induced muscular tension though a hand dynamometer. During each condition, students were 
subjected to 25 seconds of stimulation followed by a 30 second rest period. Skin temperature and pulse were recorded along a ten second interval and compared to a twominute baseline administered prior to exposure. Statistical analysis identified a significant difference between skin temperature and skin conductivity at baseline compared to the stressful stimuli situations. Physiological measures were consistent with a stressful response (i.e., increased heart rate, lower temperature, increased level of skin conductivity) in the shock condition compared to the baseline. Researchers defended their data analysis, stating it is consistent with the functioning of vasoconstriction of blood vessels when faced with a threatening stimulus. This principle dictates when experiencing a threat an individual experiences the flight or fight reaction, the body has a conditioned response marked by increased heart rate and increased skin conductance which is measurable utilizing biofeedback technology, and in essence what Cannon identified years prior.

General Adaptation Syndrome. Selye (1956) utilized Cannon's findings as a springboard for his general adaptation syndrome in which not only the sympathetic nervous system is activated in response to threat, but identified that hormones are released through the activation of the hypothalamic-pituitary-adrenal (HPA) axis in a consistent fashion. Most importantly for this investigation, Seyle's work identified in the face of a repeated stressor the HPA system does not return to homeostasis and maintains an elevated state of functioning. This state of constant hyper arousal has been shown to impact an individual's immune system in a detrimental manner. One's perception of threat activates this system that has harmful physiological effects (i.e., increased inflammation, inability to produce antibodies). This connection between the 
psychological states of being and bodily functions are referred to today as psychoneuroimmunology.

Research investigating the effects of trauma on immune system functioning in a sample of women with PTSD identified that recurrent and chronic stressors wear on the body's allostatic load (the body's attempt to maintain stability) in a significantly different manner when compared to acute stressors (Kendall-Tackett, 2009). Repeated exposure to traumatic stimuli results in continuous arousal of the HPA axis, which never is provided the opportunity to return to baseline, resulting in the release of glucocorticoids. High levels of these hormones have been shown to activate the immune system and impact a wide array of multiple system functioning, playing a role in the exacerbation of common chronic health conditions such as obesity, HIV, depression, and dementia (Raber, 1998). The constant action of the system in Kendall's study may be related to B criteria of PTSD ( $4^{\text {th }}$ ed., text rev.; DSM-IV-TR; American Psychiatric Association, 2000) and provide insight into the relationship between viewing the world as threatening and overall physical health problems. Similar research investigating the relationship between exposure to trauma, immune system response, and chronic health conditions have correlated elevated levels immune system functioning, even in healthy adult samples. The overall impact on health is immense when considering how inflammation operates as an increased risk factor across a wide breadth of conditions including coronary heart disease, chronic pain syndromes, and wound healing (Frasure-Smith \& Lesperance, 2005; Glasser \& Godbout, 2006; Pace, Hu, \& Miller, 2007; Surtees et al., 2008).

The interplay between immune system function and stress was extensively examined in a meta-analysis conducted by Segerstrom and Miller (2004). Researchers 
analyzed 293 independent studies linking stress and immune system functioning in healthy adults populations, by defining stress along five components of: time limited, brief naturalistic, event sequence, chronic, and distant. The acute time-limited stress encompassed experimental altercations of the stress response (e.g., public speaking, mental arithmetic) anywhere from 5 to 100 minutes and was characterized by an increase in natural immunity response. This sort of response is actually advantageous to an individual's health and characterized by an increase in natural killer cells and proinflammatory cytokine (IL-6). Exposure to stressful event sequences (e.g., natural disasters, death, cancer) resulted in a more heterogeneous reaction of immune system functioning. A significant decline in natural killer cells, a decrease in number of T-helper lymphocytes, and an increase in cortisol, which taken together indicates a decline in the natural immune response. These results offer further support that the immune system reacts differently to one time stressors, which is adaptive in nature, when compared to repeated stressors, which diminishes the body's ability to protect itself from infection even in a healthy population. This study clearly identifies that stress takes on a variety of forms, and when categorized it into different subsets, impact the human immune system in significantly different ways.

\section{Secondary trauma}

The classification of secondary trauma is commonly applied in conversation regarding exposure to trauma by psychologists, emergency medical technicians, or military personnel and encompasses the negative effects on an individual's mental health as a result of observing another's distress. Eidelson and colleagues (2003) define secondary trauma as, "the transformation that occurs within the therapist as a result of 
empathetic engagement with a client's trauma experiences". Other researchers have differentiated between types of trauma and intensity of reaction in professionals, specifically the largest increase in pathological symptoms being related to violence characterized by "malicious human intent and loss of life" when compared to other forms of trauma such as natural disasters (Boris, Byrne, Diaz, \& Kaniasty, 2001). The definition of secondary trauma has been broadened by others and emphasizes the change in cognitive schemas and belief systems, which is later observed through change in affect (Perlman \& Saakvitne, 1995). McCann and Pearlman (1990) (as cited in Harrison and Westwood, 2009) have defined secondary trauma with an emphasis on the role of empathetic engagement with traumatized clients, and differentiate it from burnout and counter transference. They further emphasize a change in the underlying schema of therapists, similar to Perlman \& Saakvitne, which negatively impacts emotional wellbeing and interpersonal relationships of professionals. Thus, an all encompassing definition of secondary trauma used for this study is inclusive of pathological symptoms of depression, anxiety, or those found in PTSD coupled with a change in one's underlying belief system marked by distortions or irrational thoughts, and is moderated by level of empathy.

Perhaps one of the most recent and largest traumatic events characterized by the potential of instigating secondary trauma was the September $11^{\text {th }}$ terrorist attack. In order to investigate the psychological impact in a mental health population, researchers employed statistical regression on 712 exploratory surveys completed by psychologists and mental health professionals (Eidelson, D'Alessio, \& Eidelson, 2003). Results identified the largest amount of symptoms were related to irrational fears, level of 
distress, and negative feelings towards work and were reported by professionals closest in geographical proximity to the attacks. Additionally, women reported significantly higher levels of fear compared to their male counterparts; however, when controlling for gender $71 \%$ of the sample reported being "at least slightly fearful" compared to their level of fear before the attack. Interestingly, $82 \%$ of the therapists reported a significant change in their personal lives. The utilization of open-ended questions identified change was centered on conflict in providing support for patients while personally struggling with emotions, specifically those related to loss and fear. Further analysis highlighted that professionals with the lowest level of secondary trauma received the most empathetic support from others. Such results support prior findings, identifying the protective aspect of social support in a sample of caretakers after the 2002 Oklahoma City bombing (Batten \& Orsillo, 2002). Overall, this research identifies even in a trained professional sample, negative symptoms arise when dealing with exposure to traumatic events, and that the most significant difference was reported when the acts were violent with the intent to harm or take another's life. Finally, researchers highlight the importance of an empathetic support system as a protective mechanism against the development of traumatic symptoms.

Further investigation into the effects of exposure to the September $11^{\text {th }}$ attacks in a non-professional population was conducted with 133 college undergraduate students who were exposed to the events solely through the media (Nixon \& Nishith, 2005). These students were assessed for posttraumatic symptoms one month after frequent exposure to television broadcasts of the incident; students who lost a significant friend or family member in the attack were excluded. Statistical analysis utilizing regression across 
the Acute Stress Disorder Scale, Beck Depression Inventory, Posttraumatic Cognition Inventory, and a history of trauma survey identified negative cognitions of the self and the world mediated PTSD and depressive symptoms. Additionally, depression symptoms functioned as a mediator between prior reports of trauma and negative thoughts of the self; prior trauma was also predictive of negative thoughts of the world. Overall, the analysis identified negative posttraumatic thoughts influenced the development of trauma symptoms, which was also associated with depressed mood. Thus, Nixon and Nishith emphasized the importance of cognitions in the later development of PTSD symptoms in a non-clinical college sample exposed to trauma through the media.

Figley (1995) has established a similar construct to secondary trauma called secondary traumatic symptoms (STS), which is related to the effects of caring for others in emotional pain that later leads to specific PTSD symptoms. Utilizing both Figley's and McCann's ideology focusing on PTSD symptoms and change in cognitive beliefs, Harrison and Westwood (2009) employed a structured and narrative interview of six professionals with an extensive history of working with traumatized clients to identify protective factors against the development secondary traumatic stress. Figley identified major themes including: sense of community in professional, personal, and spiritual aspects of life; quality of training; diversity of professional roles; mindfulness; challenging negative cognitions; optimism; holistic self care; maintenance of boundaries; empathy; professional satisfaction, and creating meaning in life. Overall, statistical analysis identified empathetic engagement with clients as a significant protective factor. When questioned about the nature of empathy, professionals reported feeling "invigorated" by being closely involved with their clients. This study challenges previous 
literature that claims empathetic involvement operates as a risk factor for the development of secondary trauma.

To further investigate the level of secondary trauma, Brady, Guy, Poelstra, \& Brokaw (1999) conducted a nationwide survey of 446 female psychotherapists working with clients that have a history of sexual abuse. The assessment addressed areas of workrelated characteristics, involvement in personal therapy, personal trauma history, the Impact of Events Scale, the Traumatic Stress Institute Belief Scale, and the Spiritual Well-Being Scale. The therapists ranged in educational level from $\mathrm{MS}$ to $\mathrm{PhD}$ and years of experience from 0-35 with an average of 11 years, and a broad range of abuse training hours. Brady and colleagues investigated report of PTSD symptoms (i.e., intrusive imagery, change in affect) and changes in cognitive schemas (i.e., altering one's view of the world, identity, and spirituality) as a measure of secondary trauma. Researchers completed an ANOVA analysis that identified greater exposure was associated with higher levels of PTSD symptoms, but that exposure was not related to changes in cognitive schemas. Interestingly, psychotherapists who reported the highest exposure to trauma also reported the highest level of spiritual well being. In therapists reporting PTSD symptoms, exposure was characterized as including graphic details, cruelty, consecutive sessions of trauma processing, and reenactment experiences of the trauma. Finally, exposure to working with children that were exposed to trauma was correlated with the development of feelings of helplessness, rage, and a desire for retaliation. Overall, this study contributes to the findings that it is not merely exposure to trauma, a personal history of trauma, or level of training in how to cope with trauma, but rather the nature of the trauma as well as the age of the victim. 
The impact of exposure to victims of violence has also been examined utilizing self-report questionnaires across a wide variety of professionals $(n=259)$ including social workers, nurses, occupational therapists, physicians, psychologists, and chaplains in a Canadian population (Bober \& Regehr, 2006). Professionals ranged in education from possessing bachelors to doctoral degree, with an average of 10.17 years of counseling experience. Measures included the Impact of Events Scale, the Traumatic Stress Institute Belief Scale, and the Coping Strategies Inventory. Factor analysis found that age of professionals was negatively associated with development of trauma symptoms, which was mainly observable in PTSD avoidance behavior. Additionally, the more direct client contact hours were significantly positively related with symptoms of intrusion. The nature of the trauma also influenced the severity and presence of secondary symptoms; those working with victims of child abuse, sexual violence, and torture reported significantly higher levels of trauma symptoms. Researchers also drew attention to aspects of protective factors and identified involvement in leisure activities countered the development of symptoms. When considering the nature of the trauma, exposure to wife assault, child abuse, rape, and torture also yielded the most significant changes in cognitive belief systems. This study revealed age and amount of direct client contact as risk factors for the development of PTSD symptoms, specifically avoidance and intrusive thoughts. Interestingly, researchers identified that exposure to certain types of trauma impact cognitive schemas more severely. Thus, mere exposure is more detrimental to certain young therapists, but specific topics result in more intense secondary symptoms.

The emotional changes that transpire in therapists as a result of working with perpetrators of sexual violence were examined as a catalyst to secondary trauma by 
Carmel \& Friedlander (2009). The sample was composed of therapists (n=106) who ranged in age from 26 to 68 , and all specialized in treating forensic populations.

Therapists averaged 12.7 years of clinical experience with a range of $0.83-38$ years. Secondary trauma was measured using the Working Alliance Inventory-Short Form, the Professional Quality of Life Scale, the Impact of Event Scale-Revised, and a demographic questionnaire. Other symptoms of secondary trauma included a decrease in hope, increase of cynicism and pessimism, emotional numbing, and affective distancing. Regression analysis identified therapists with low scores on secondary symptoms were characterized as deriving the highest amount of satisfaction from their compassionate reaction within the therapeutic relationship, or in other words those with the highest level of empathy. Researchers emphasized that therapists in the sample generally reported none or very few secondary trauma symptoms, and those who develop such symptoms may remove themselves from the field. Overall, exposure to perpetrators of violent crime appeared to additionally influence the development of traumatic symptoms; however, symptoms were different than those observed in professionals exposed to working with victims of such crimes.

Finally, analysis of secondary trauma in mental health professionals was investigated in a sample of 129 graduate students during their training in a clinical and counseling psychology program (Adams \& Riggs, 2008). Perlman and Saakvitne (1995) previously reported, the absence of formal coursework addressing affective responses in working with clients that present with traumatic histories places students at an increased risk to later PTSD symptoms. Adams hypothesized that secondary trauma was moderated by empathetic engagement with the client that later has a detrimental influence on the 
therapist's personal relationships due to increases in anxiety, depression, somatic complaints, emotional numbing, and avoidance. Adams further investigated how exposure to trauma in unprepared therapists impacted their coping styles. Students were administered the Trauma Symptom Inventory (TSI), the Defense Style Questionnaire, and an exploratory experience questionnaire. One fourth of the students reported working with trauma clients with no prior training specific to trauma, and over a third of the sample reported being victims of trauma. Over one third obtained scores on the TSI that were clinically significant, confirming this report. Statistical analysis additionally identified $7 \%$ of the students reported a maladaptive defense style marked by regression, acting out and/or splitting, which was correlated with the higher TSI scores. Such defenses have previously been documented and characterized as restrictive in nature, inclusive of denial and numbing that is associated with distancing from the client and maladaptive behaviors of impulsivity, rescue attempts, or boundary violations (Herman, 1997). Multiple ANOVAs were conducted along defense styles and reveled students with a self-sacrificing coping style who were more altruistic obtained higher scores on the TSI, and thus deemed more vulnerable to developing secondary trauma. Overall, research by Adams and colleagues draws attention to the need of proper training in young therapists prior to working with traumatized clients; however, that certain personality characteristics such as altruism may also operate as a moderating variable in the development of PTSD symptoms.

A different aspect of secondary trauma considers the transmission of symptoms within an interpersonal relationship. Dirkzwager, Bramsen, Ader, and Van der Ploeg (2005) examined the development of trauma symptoms as a result of intimate 
involvement with those who are exposed to trauma, such as active duty military or police officers. Researchers identified that female spouses with male solider counterparts with a diagnosis of PTSD reported significantly more symptoms themselves when compared to spouses of non-PTSD soldiers. These women additionally reported significantly greater symptoms of PTSD when compared to parents or siblings of a solider. The phenomena of the development of symptoms in spouses from military peacekeepers has also been referred to within the literature as posttraumatic stress syndrome (PTSS), and has been positively correlated to the level of PTSD with the military partner (Jordan, et al., 1992; Solomon et al., 1992). Dirkzwager et al., (2005) concluded baseline physical health, relationship quality and length, circumstantial stressors, and levels of social support are significant factors influencing the development of PTSS. Those with comorbid health symptoms, involved in shorter relationships, financial and legal instability, and lacking social support are more likely to develop PTSS. Additionally, the relationships in which the partner presents with PTSS were characterized as being more problematic and socially isolated than those with partners who did not develop such symptoms. Researchers hypothesized PTSS is observed in this population because they operate as the primary support system for the individual with PTSD, and possess elevated levels of empathy with their significant other. This heightened state of empathy partnered with a reduction of resiliency after caring for their significant other places them as at risk for PTSS. Overall, this study emphasizes that an individual may develop PTSD symptoms without direct exposure to a trauma to the extent where it results in clinical symptoms that still significantly impacts quality of life, and is moderated by level of empathy. 


\section{Impact of exposure to trauma in media}

The American culture is highly involved in the media as a source for news and entertainment, and as a result millions are now directly exposed to terrorist attacks, war, and horrific violence on a daily basis. The news repeatedly plays unedited cycles of gruesome crimes related to rape, murder, and large-scale destruction that have been labeled as "harmful to the public" (Slone \& Shoshani 2008). The use of such media subjects viewers to intimate aspects of crimes that change consumer's cognitive belief systems and result in psychological consequences commonly identified as a loss in the sense of security and an increase in fear (Sontag, 2005). The impact of such exposure has been considered regarding both short and long term effects, with short term changes characterized by an increase in distress, shock, fear, panic, and avoidance of public places (Lawyer, Resnick, Galea, Ahern, Kilpatrick \& Vlahov, 2006). Long-term effects on the other hand, parallel symptoms consistent with posttraumatic stress disorder. The spectrum of changes in behavior and emotion have previously been documented after the 1993 World Trade Center bombing (Ofman, Mastria \& Steinberg, 1995), the 1995 Oklahoma City bombing (Pfefferbaum, et al., 2001) and most recently the September $11^{\text {th }}$ attacks (Ahern et al., 2002; Cho et al., 2003) and are characterized by symptoms of depression, anger, anxiety, and feelings of insecurity. The impact of recordings from September $11^{\text {th }}$ may even be deeper than initially considered. Media exposure has been associated with the creation of aggressive cognitive scripts, hostile attribution biases, and aggressive beliefs (Huesmann, Moise-Titus, Podolski \& Eron, 2003). Additionally, viewing similar material early in life has shown to predict later behavioral aggression on part of the viewer (Huesmann et al., 2003; Coyne \& Archer, 2005). Researchers also have 
investigated the effects of viewing September $11^{\text {th }}$ tapes in relation to unconscious processing, specifically through dreams (Propper, Strickgold, Keeley \& Chrisman, 2007). Propper and colleagues observed for every hour of exposure to September $11^{\text {th }}$ material in the news, there was an observed five to six percent increase in September $11^{\text {th }}$ dream references. Such findings propose the media not only impacts presentation of symptoms and changes in cognitive structures, but also the unconscious processes of viewers.

The negative effect of exposure to media violence specific to children has been investigated since the 1940s. In 1972 the U.S. Surgeon General stated violence on television has an "adverse effect on certain members of society" in the discussion about children and the media. Major scientific bodies in the medical community including the American Psychological Association, the American Medical Association, and American Academy of Pediatrics agree there is a connection between violence in the media and aggressive childhood behavior (Joint Statement, 2000). A recent meta-analysis looking at media violence and aggression, regardless of experimental method employed, shows a clear positive link between exposure and violent behavior (Bushman \& Anderson, 2001). The effects of media on behavior are also evident through reduction of television hours viewed per week. Jordan and colleagues (2006) identified a significant reduction in aggressive behavior in third and forth grade students across a six-month period after the employment of a television restriction intervention. This study highlights a significant relationship between television exposure and behavior, and additionally has serious implications on the repetitive nature of reporting in the news.

The everyday technology that has infiltrated the lives of Americans has allowed for the exposure to trauma to effortlessly transpire through the media, Internet, and 
cellular devices. The most recent glaring example of this being exposure to audio and video recordings of the September $11^{\text {th }}$ attacks. As a result, there have been documented reactions in viewers similar to PTSD, and some researchers have even called for the creation of a spectrum scale of PTSD for diagnostic purposes (Terr, Bloch, Michel, Shi, Reinhardt \& Metayer, 1999). Such an argument is based on previous literature that concluded pure television exposure to events similar to city bombings being linked to posttraumatic stress symptoms (Nader, Pynoos, Fairbanks, Al-Ajeel \& Al-Asfour, 1993). Taking a closer look at the manifestation of symptoms, research conducted by Pfefferbaum \& colleagues (2003) assessed if sixth grade students $(\mathrm{N}=119)$ up to 100 miles away from the Oklahoma City bombing experienced a reaction that was measurable by utilizing PTSD diagnostic criteria. Researchers designed an instrument measuring physical, interpersonal, and media exposure to the incident as well as reaction to the media and PTSD symptoms. The measure of posttraumatic stress was based upon questions from the Impact of Events Scale- Revised edition. Analyses revealed that indirect exposure to the event through the media was significantly correlated with measures of posttraumatic stress. No significant difference was seen in symptoms across gender, yet a trend was identified that girls reported a higher emotional reaction than boys. Trauma symptoms fell into the average range, yet many students reported feeling symptoms "very frequently" and within the past week. Such reactions included feeling irritable, intrusive thoughts of the event, intrusive imagery, avoidance of thoughts, and experiencing waves of strong emotions towards the bombing. Overall, researchers concluded regardless of the fact if children had any interpersonal exposure, (i.e., knowing someone who died) react with an increase in PTSD symptoms to terrorist attacks, and 
that children with heightened states of arousal were at an increased risk of developing and reporting such symptoms.

The influence that such traumatic television reports have on our nation's children was further investigated following the 1995 Oklahoma City bombing by Pfefferbaum, Nixon, Tivis, Doughty, Pynoos, Gurwitch \& Foy in 2002. Students $(n=2,000)$ from 11 middle schools in the Oklahoma City public school system were recruited from sixth to eighth grade. A 56-item survey was designed that measured physical and emotional symptoms, posttraumatic stress symptoms (questions were utilized from the Impact of Events Scale- Revised), and amount of television exposure. Regression analysis was used to create a "non-exposed group" which teased out students that did not hear or feel the explosion, or know someone who had been killed or injured from the bombing. This group was then utilized as a comparison group to the exposed group on their level of television exposure and symptom presentation. Descriptive statistics indicated two thirds of the students heard or felt the explosion, and half knew someone who had been wounded or killed. The intercorrelations reveled that television exposure accounted for $6 \%$ of the posttraumatic symptoms, $7 \%$ of intrusion symptoms, $3 \%$ of avoidance symptoms and $4 \%$ of arousal. This was greater than physical exposure that accounted for $3 \%$ of posttraumatic symptoms, $4 \%$ of intrusion, $3 \%$ of arousal, and $1 \%$ of avoidance. This study identifies the strong psychological effects that transpired due to constant media coverage of the bombing incident and how this was significantly related to posttraumatic stress symptoms. Taking a closer look at hours viewed, researchers emphasized that higher symptomatic children viewed more television, when controlling for other factors such as age or gender. This finding alone suggests in children the impact 
of repeated media exposure may actually have a greater effect than being physically exposed to a single incident of trauma.

Adopting a global perspective and looking at cultures with histories of long-term repeated exposure to violence and human suffering in the media, researchers investigated the psychological effects of exposure to terrorist attacks in 913 Israeli adolescents (Braun-Lewensohn, Celestin-Westreich, Clestin, Verte \& Kristoffersen, 2009). Students age 12 to 18 were recruited from four different locations in Israel and represented children from both rural kibbutzim and urban settings. Measures included an exposure to terror and posttraumatic stress questionnaire designed for the study, the Global Objective Exposure Index, the Subjective Exposure Index, near miss experiences, level of media exposure, the Post-Traumatic Stress Index, Achenbach's Youth -Self Report, and the Brief Symptom Inventory. Statistical analysis showed two thirds of the students reported objective exposure; one third of adolescents having a relationship with a victim of trauma, and one third endorsed having a personal near miss experience. As hypothesized, all forms of exposure were significantly associated with reports of posttraumatic stress symptoms and also significantly correlated with behavioral and emotional problems for subjective and objective exposure, yet not for media exposure. Stepwise regression revealed the more adolescents viewed the media the less they experienced behavioral and emotional problems. Similar findings have been reported that focus specifically on physical exposure and psychological reactions in terms of PTSD symptoms, anxiety, and later behavioral problems such as substance abuse (Hoven et. Al., 2002; Koplewica et al., 2002; Laufer \& Solomon, 2003; Schiff et al., 2007), and that this relationship is not always unidirectional. In fact, some individuals report fewer symptoms even though they 
were subjected to more trauma related media. Solomon and colleagues (2005)

investigated the counterintuitive direction of this relationship and reported that it is not the amount of exposure that plays a pivotal role in later posttraumatic symptoms but rather an individual's view of the media as less objective and more fear inducing (Solomon et al., 2005). Regression analysis by Braun-Lewensohn and colleagues defined a clear distinction between the constructs of subjective and objective exposure, and identified subjective experience of trauma was significantly related to psychological symptoms. Essentially, the thoughts and feelings surrounding the event had the largest impact on later health, and not the act itself. These results are counter to findings in the United States (Hoven et al., 2004; Pfefferbaum et. al., 2001), where it was observed in a sample of American children the amount of exposure to traumatic media was positively correlated with the development of PTSD symptoms. The authors argued since the news culture in Israel is characterized by more graphic violence children are familiar to the nature of the coverage and do not perceive it to be traumatic. Thus, it appears as if the authors argue that repeated exposure leads to desensitization of reaction to such media coverage. It is of importance to emphasize the study in the United States was conducted after a single large terrorist attack, and not after long periods of repeated exposure in which the cumulative effect may have a different impact on psychological health.

Another international study aimed to assess changes in anxiety and anger included 168 university students from Tel Aviv University, and exposed them to terrorist or nonterrorist related media clips (Slone \& Shoshani, 2008). Researchers employed the StateTrait Anxiety Inventory, the State-Trait Anger Expression Inventory and two seven minute movies that were composed of clips from the local news programs. Half of the 
participants were additionally provided a one-hour therapeutic intervention designed to reduce stress after exposure to the media clips, while the other half engaged in a group activity that avoided discussion of the tapes or associated emotions. Two ANCOVAs were conducted considering differences between type of media exposure, as well as type of intervention. Results revealed that exposure to terrorist related media yielded higher levels of anger and anxiety compared to just local news. Additionally, in those who obtained the stress reduction therapy after exposure, significantly lower levels of anxiety and anger were reported in the terrorism media condition when compared to individuals in the group activity. The significant increase in these emotions is in line with the researcher's hypothesis that mere exposure to media coverage of this nature has a negative psychological impact on the general population, yet this can be corrected with as little as one hour of therapeutic intervention. Researchers cautioned since such violence is constantly presented in the media, it might create a long-term sense of insecurity and become a chronic stressor, which no longer is adaptive for survival of the individual and results in elevation of pathological symptoms.

Further investigation into the pattern of manifestation of posttraumatic stress symptoms in adults was conducted after the threat of anthrax attacks following September $11^{\text {th }}$. Researchers at the University of Pittsburgh assessed the reaction of 300 individuals after the anthrax mailings in a geographical location near the incidents (Dougall, Hayward \& Baum, 2005). Participants were randomly recruited from a mailing list of 5,000 zip codes near the university. Mailings included informed consent as well as a booklet of questions; participants who responded were then again mailed at a six-month follow up. The booklet included questions that addressed exposure to anthrax attacks, 
perceived risk of anthrax exposure, changes in outlook, measured by the World Assumptions Scale as well as Change in Outlook Questionnaire, and psychological distress symptoms, which included questions from the Daily Record Form and the Impact of Event Scale. Initial examination of correlations revealed significant relationships between lower reports of distress symptoms and being married, male, older, and having a higher level of education. Utilizing repeated measures MANCOVA, and controlling for age, gender, marital status and education, the only variable that was related to distress was initial anthrax media exposure. This finding identifies that the amount of media coverage participants viewed when first finding out about the attacks predicted the later posttraumatic response marked by characteristics of stress, intrusion, and avoidance symptoms. An additional MANCOVA was conducted controlling for the same covariates, to assess how outlook changed as a function of media exposure. A significant increase in the amount of negative outlook was observed due to both initial exposure, and at six-month follow up. Thus, a continuous change in negative outlook and altercation of cognitive beliefs continued to decline across the six-month period. Finally, a significant difference utilizing a third MANCOVA was observed in perceived risk of exposure to the self as well as family members as a function of media exposure; those who initially watched more media related to the anthrax attacks, reported significantly greater concern over personal exposure. Overall, results help to clarify that people who were not directly affected by the attacks still experienced a distress reaction, with initial media exposure functioning as a predictor of such distress. Additionally, the more frequent the exposure the more intense the stress reaction marked by both psychological symptoms as well as changes in worldview, such as a loss of trust in others. Interestingly, the six-month follow 
up assessing worldview, identified all participants adopted a more negative view about life; however, those who reported not watching anthrax related media coverage indicated the least negative change.

Finally, the most recent highly televised trauma of the Virginia Teach shootings was investigated by Fallahi and Lesik (2009) in 312 psychology undergraduate and graduate students that were strictly exposed to the violence through the media with the intent to obtain similar findings after the Oklahoma City bombing (Pfefferbaum, Seale, et al., 2000). The average student was 19.56 years of age, Caucasian (82.1\%) with a GPA of 3.00. Researchers assessed how many hours of news students watched that specifically addressed the Virginia Tech shootings, and asked participants to rate symptoms of depression, anxiety, and stress related symptoms that were adopted from the DSM-IVTR. The survey additionally measured symptoms of acute stress disorder that was also taken from the symptom list of the DSM-IV-TR. A multinomial logit model was conducted comparing categories assessing the main criteria of the PTSD symptom groups. The model showed that as the amount of TV exposure to the Virginia Tech shootings increased so did participant reports of intrusive thoughts, sleep issues, distraction, fear, somatic symptoms, depression, disorganization in thoughts, and anger. Most interestingly, a clear relationship was developed between number of hours watched and reported symptoms with the odds of experiencing acute symptoms increasing from 1.48 to 3.20 times for each hour of television watched. Results revealed that even three weeks after the shooting incident, PTSD symptoms were reported to a significantly high degree in a sample of successful and healthy college students. The obtained odds ratio is useful for future research in predicting symptoms after exposure to trauma in the media, 
and sheds light on prevention by turning the television off or removing repeated broadcasting.

\section{Current Study}

The problem addressed by the current study is if physiological and psychological arousal as a result of exposure to news coverage including 911 emergency phone call recordings is significantly different than news coverage without such traumatic recordings.

\section{Hypotheses}

1. It was hypothesized that higher levels of physiological arousal would be observed in the 911 emergency phone call condition compared to the news condition.

2. It was hypothesized in the 911 emergency phone call condition that higher levels of physiological arousal would be observed in individuals reporting higher levels of negative mood states, assessed by the Profile of Mood States (POMS) (see Appendix A), when compared to report of a positive affective state.

3. It was hypothesized that personality factors according to the NEOPersonality Inventory Revised edition (NEO PI-R) (see Appendix B) and the Multi-Dimensional Emotional Empathy Scale (EES) (see Appendix C) would predict physiological arousal while controlling for the influence of age and gender on level of arousal.

4. It was hypothesized that individuals with a high baseline score on the PTSD Checklist Civilian Version (PTSD-C) (see Appendix D) 
displayed higher levels of physiological arousal in the 911 emergency phone call condition.

\section{CHAPTER III}

The current study utilized data gathered by the principal investigator that evaluated the physiological and psychological response after exposure to news related audio stimuli at the Nova Southeastern University Psychological Services Center in Fort Lauderdale Florida. The following information describes the participants and the measures. For more detail on validity and construction of the measures included in the psychological battery, please refer to the provided citations of original authors.

\section{Method}

\section{Subjects}

One hundred adults enrolled as students at Nova Southeastern University were used for this study. The students were distributed along the lines of gender, age, ethnicity, and area of concentration in educational career. Individuals who were deaf or hearing disabled were excluded from the investigation due to the auditory nature of the stimuli.

\section{Inclusion and Exclusion Criteria}

For purposes of this investigation, a range of zero to five microvolts was established in measurement of GSR across all conditions. Data residing outside of these values were deemed to be representations of experimental artifact. Such artifact is manifested by a variety of factors including participant movement of sensors during the data-gathering phase, poor connectivity of GSR sensors to skin, or absence of connectivity. The BioTrace software was programmed to automatically remove such 
artifact, resulting in the exclusion of GSR points in twenty participants. Furthermore, GSR data was not utilized for one participant as a result of a biological diagnosis of hyperhidrosis.

All collected data for heart rate and respiration were within normal range of a resting state at time of initial baseline and thus included for utilization in data analysis. Failure to record heart rate transpired in two recording sessions. No data was lost or jeopardized regarding respiration rate. Finally, two of the 100 participants failed to complete the entire battery as a result of removing themselves from the experiment for personal reasons not associated with the investigation. Of the 100 original participants, 76 were utilized for data analysis. The sample was predominately female $(n=55)$, graduate level students with the average age of 25.98 years $(18-44 ; \mathrm{SD}=4.45)$.

\section{Measures}

PTSD Checklist Civilian Version. The PTSD Checklist Civilian Version (Weathers, Litz, Herman, Huska \& Keane, 1993) is a 17 item self-report measure that parallels the 17 DSM-IV- TR symptom criteria for PTSD and requires five minutes to complete. The form utilizes a five-point scale ranging from "Not at all" to "Extremely". It has been widely used as a screening instrument to diagnose PTSD, monitor symptom change in response to treatment, and in research. The instrument has strong psychometric properties with Chronbach's alpha ranging between .94 and .97 and test-retest reliability after three days of .96 and .88 after one week. Sample questions include: "Loss of interest in activities that you used to enjoy", "Feeling very upset when something reminded you of a stressful experience from the past", and "Feeling distant or cut off from other people". 
Profile of Mood States. The Profile of Mood States (McNair, Loor \& Droppleman, 1971) is a 65-item self-report questionnaire based on a 5-point scale ranging from "Not at all" to "Extremely" that rates the mood state the respondent is experiencing either over the past week, today, or right now. The instrument is composed of 6 mood factors: tension-anxiety, depression-dejection, anger-hostility, vigor-activity, fatigue-inertia, and confusion-bewilderment. The instrument was normed across four samples $(\mathrm{n}=2,400)$ including psychiatric outpatients, adults, college students and geriatric adults. Numerous research studies have produced high alpha coefficients for internal consistency and high correlations to indicate test-retest reliability. Sample mood states include: "Friendly", "Grouchy", "Hopeless" and "Lively".

NEO Personality Inventory- Revised. The NEO PI-R (Costa \& McCrae, 1992) is a measure of five major domains of personality including neuroticism, extraversion, openness to experience, agreeableness, and conscientiousness and further breaks each down into six factors. Test retest reliability across all scales is above .75 . The form consists of 240 items answered on a five-point scale, ranging from "strongly disagree" to "strongly agree". The internal consistency presented in the manual $(\mathrm{n}=1,539)$ was high at: $\mathrm{N}=.92, \mathrm{E}=.89, \mathrm{O}=.87, \mathrm{~A}=.86, \mathrm{C}=.90$. Sample questions include: "She's pretty set in her ways", "She's an even-tempered person", and "He often enjoys excitement".

Multi-Dimensional Emotional Empathy Scale. The Multi-Dimensional Emotional Empathy Scale (EES) (Caruso \& Mayer, 1998) is a 30 item, five point Likert scale ( $1=$ strongly disagree $)$ to $(5=$ strongly agree $)$ self-report measure that has been cross validated with the Balanced Emotional Empathy Scale (BEES; Mehrabain, 1996), the Afflictive Tendency Scale (MAFF; Mehrabian, 1994), the Self Report Delinquency Scale 
(SRDSG; Gibson, 1971), and the Trait Emotional Awareness Scale (TEAS). Analysis from discriminant and convergent validity across all four measures provide strong evidence for the validity of the EES in measuring an individual's level of empathy. Sample questions include: "I feel like crying when watching a sad movie", "My feelings are my own and do not reflect how others feel", and "I feel other people's pain".

BioTrace Biofeedback. The biofeedback software, BioTrace (MindMedia, 20042008), has been designed and used in a variety of research fields including physiological, psychophysiological, neuropsychological, and biofeedback. BioTrace software utilizes Nexus version 10 hardware to process, gather, visualize, and record signals once sensors are applied to the subject. All instruments are based on 24-bit precision and use carbonshielded electrodes with the ability to cancel out noise to detect signals. The product line is medical grade (device class IIa, CE 93/42/EEC) and manufactured under the standard ISO13485 and FDA QSR. The information gathered from the system is deemed to be highly reliable and gathered at a sample rate of 2048 per second. Additionally, there is no calibration required, thus the hardware is guaranteed to work within certain amplitude ranges (less than 0.2 microvolt to $1,000 \mathrm{Hertz}$ ) without introducing an element of human error.

\section{Procedures}

Participants were recruited through flyer advertisements in spaces that students employ as common areas whose title read, "A study is being conducted examining the effects of 911 Emergency Tapes". Individuals were directed to email the primary investigator if interested in volunteering for the investigation. Participants were 
additionally recruited though lectures established with professors in the psychology undergraduate and graduate departments.

After email contact with the primary investigator, individuals established private one-hour sessions in the biofeedback lab within the Psychological Services Center at times that reflected the best availability within their schedules. Participants arrived at the lobby of the building and were escorted into the lab by the primary investigator. At this point, participants were provided with informed consent as well as associated HIPPA documents and any questions or concerns were addressed prior to administration of psychological measures and exposure to the audio condition.

\section{Consent}

The informed consent documents included information regarding the purpose of the investigation, as well as the risks and benefits associated with participating. The risks were minimal in nature and included mild emotional discomfort as a result of listening to the audio condition, and mild physical discomfort from the chest strap and finger sensors. Enrollment in the investigation was entirely voluntary and there was no cost involved for participation with the exception of approximately one hour of time, to which individuals were compensated fifteen dollars.

All participants were provided with the informed consent at the onset of the testing session as well as verbally informed as to its consent; all consent forms were reviewed, the study described, and all questions answered prior to the participant's signature; this transpired in a private therapy room reserved for biofeedback intervention and therapy. Additionally, given the nature of the data collected, participants were provided with a HIPPA document highlighting the protection of their health information 
and confidentiality of their output. Participants were also provided with verbal instructions regarding the coding of their data and assured that their name was not attached to any of the output, but rather a research number. Prior to onset of the psychological battery and audio condition, participants were reminded of the potential risks and benefits and the right to discontinue the session at any point in the administration of battery.

At this time the PTSD-C was administered followed by the ESS. Participants then had the biofeedback equipment placed on their fingers (one sensor for heart rate and two for galvanic skin response), as well as a chest strap to monitor respiration rate. A twominute period of silence transpired to establish a baseline for each participant. After this initial baseline period the audio recording was initiated; each condition lasted three minutes followed by another two-minute period of silence to measure return to baseline. The audio files were presented in the order of news report, followed by a neutralizing stimulus, and concluded with the 911 emergency recording. This presentation was utilized to ensure the mood reported on the POMS was a reflection of the 911 emergency call condition as a result of the recency effect. This order allowed for the avoidance of presentation of any stimuli that would have an interference effect on the post-exposure psychological battery. After the conclusion of the audio exposure, the apparatus was removed and the POMS and NEO PI-R were administered. Upon completion of all psychological assessment measures the participants were provided with fifteen-dollars in monetary compensation, and any questions regarding participation in the study were addressed. 


\section{Chapter IV}

\section{Results}

Prior to testing the hypotheses of the study, distribution of scores across all variables was assessed for the assumptions of normality and linearity. After examination of such tests, no divergence from normality was observed.

Hypothesis one. The hypothesis that higher levels of physiological arousal were observed in the 911 phone call condition compared to the news condition was analyzed using three independent paired t-tests. The mean scores on each physiological measure (beats per minute for heart rate, microvolts for GSR, and breaths per minute for respiration rate) were compared across the two audio conditions.

Significant differences between GSR in the news $(\mathrm{M}=1.32, \mathrm{SD}=.79)$ and the 911 phone call condition $(\mathrm{M}=1.13, \mathrm{SD}=.76), \mathrm{t}(75)=3.67, \mathrm{p}<.01$ were obtained. This difference was medium in effect size, Cohen's $d=.42$, indicating lower levels of GSR in the 911 condition, which translates into an elevated stress response. Significant differences were also observed between respiration rate in the news $(M=15.20, S D=4.16)$ and 911 phone call condition $(\mathrm{M}=17.00, \mathrm{SD}=4.34), \mathrm{t}(75)=-6.35 \mathrm{p}<.01$. The difference was medium in effect, Cohen's $d=.72$, and reveals a higher level of respiration in the 911 phone call condition. Finally, significant differences were not observed for heart rate in the news only condition $(\mathrm{M}=78.38, \mathrm{SD}=12.55)$ and the 911 phone call condition $(\mathrm{M}=77.94, \mathrm{SD}=12.21), \mathrm{t}(75)=1.45, \mathrm{p}=.15$, with minimal effect size, Cohen's $\mathrm{d}=.17$. These results suggest that heart rate did not vary across the two conditions.

Hypothesis two. The hypothesis that higher levels of physiological arousal were observed in individuals who reported higher levels of negative mood states, as opposed to positive 
mood states, was examined with Pearson's correlations. Table 1 displays the descriptive statistics for reports of mood state. As seen in Table 2, respiration rate was significantly positively correlated with all negative mood states to a medium degree, but not with the positive mood state. This correlation indicates that higher levels of respiration rate were observed in those who reported higher levels of negative mood states and not positive state. Additionally, Table 2 highlights heart rate and GSR were not significantly correlated with either negative or positive mood state.

\section{Table 1}

Descriptive Statistics for Mood State as Measured by the POMS and Arousal (N=76)

\begin{tabular}{lll}
\hline Mood State & M & SD \\
\hline T & 55.145 & 11.744 \\
D & 49.342 & 8.233 \\
$\mathrm{~A}$ & 46.947 & 9.134 \\
$\mathrm{~F}$ & 46.566 & 7.767 \\
$\mathrm{C}$ & 51.026 & 8.624 \\
$\mathrm{~V}$ & 35.829 & 6.531 \\
$\mathrm{HR}$ & 78.122 & 12.179 \\
GSR & 1.132 & .758 \\
RESP & 17.058 & 4.343 \\
\hline
\end{tabular}

Note: T= Tension-Anxiety; $\mathrm{D}=$ Depression-Dejection; A= Anger-Hostility; F=FatigueInertia; $\mathrm{C}=$ Confusion-Bewilderment; $\mathrm{V}=$ Vigor-Activity . 
Table 2

Correlations Between Arousal in the 911 Emergency Call Condition and Mood State $(N=76)$

\begin{tabular}{lllllll}
\hline & HR & $\mathrm{p}$ & GSR & $\mathrm{p}$ & RESP & $\mathrm{p}$ \\
\hline $\mathrm{T}$ & .148 & .201 & .003 & .976 & .312 & .006 \\
$\mathrm{D}$ & .152 & .191 & .043 & .693 & .326 & .004 \\
$\mathrm{~A}$ & -.007 & .950 & .049 & .676 & .310 & .006 \\
$\mathrm{~F}$ & .124 & .284 & -.025 & .830 & .341 & .003 \\
$\mathrm{C}$ & .202 & .080 & .064 & .585 & .374 & .001 \\
$\mathrm{~V}$ & -.187 & -.106 & .006 & .960 & -.153 & .187 \\
\hline
\end{tabular}

Note: $\mathrm{T}=$ Tension-Anxiety; $\mathrm{D}=$ Depression-Dejection; $\mathrm{A}=$ Anger-Hostility; F=Fatigue-

Inertia; $\mathrm{C}=$ Confusion-Bewilderment; $\mathrm{V}=$ Vigor-Activity.

Hypothesis three. The hypothesis that personality factors would be correlated with physiological arousal in the 911 phone call condition was analyzed using semipartial correlations across each of the three arousal states, while controlling for influence of age and gender on arousal. As seen in Table 3, no significant correlations were obtained between GSR, heart rate, respiration rate and personality characteristics. 
Table 3

Semipartial Correlations Between Arousal and Personality Characteristics $(N=76)$

\begin{tabular}{lllllll}
\hline & GSR $(\mathrm{sr})$ & $\mathrm{p}$ & $\mathrm{HR}(\mathrm{sr})$ & $\mathrm{p}$ & $\mathrm{RESP}(\mathrm{sr})$ & $\mathrm{p}$ \\
\hline $\mathrm{N}$ & .136 & .242 & .133 & .241 & .183 & .106 \\
$\mathrm{E}$ & -.173 & .134 & -.151 & .192 & .168 & .145 \\
$\mathrm{O}$ & -.071 & .539 & -.048 & .678 & -.125 & .275 \\
$\mathrm{~A}$ & -.116 & .320 & -.191 & .100 & -.025 & .830 \\
$\mathrm{C}$ & .111 & .326 & -.113 & .313 & -.051 & .653 \\
$\mathrm{Em}$ & -.134 & .229 & .057 & .606 & .118 & .288 \\
\hline
\end{tabular}

Note: $\mathrm{N}=$ Neuroticism; $\mathrm{E}=$ Extraversion; $\mathrm{O}=$ Openness to Experience; $\mathrm{A}=$ Agreeableness;

$\mathrm{C}=$ Conscientiousness; Em=Empathy; (sr)= semipartial correlation.

Hypothesis four. The hypothesis that individuals with a high baseline score on the PTSD-

C would display higher levels of physiological arousal in response to the 911 emergency

phone call condition was examined using three Pearson's correlations. As observed in

Table 4 , respiration rate was the only measure of arousal significantly positively

correlated with baseline level of PTSD. This relationship indicates those with higher

scores yielded higher levels of respiration in response to the 911 phone call condition. 
Table 4

Correlations Between Arousal and PTSD-C Score $(N=76)$

\begin{tabular}{lllll}
\hline & PTSD & $\mathrm{p}$ & $\mathrm{M}$ & $\mathrm{SD}$ \\
\hline PTSD & ------ & ----- & 32.316 & 12.066 \\
HR & -.092 & .427 & 78.122 & 12.179 \\
GSR & -.077 & .508 & 1.132 & .758 \\
RESP & $.235^{*}$ & .040 & 17.058 & 4.343 \\
\hline
\end{tabular}

Post Hoc Analyses.

Post hoc exploratory analysis was conducted examining the difference in arousal states from initial baseline to post exposure baseline to determine if individuals were able to sustain arousal and model Seyle's adaptation theory. Again, three paired t-tests were performed to compare the means of each arousal state across the two conditions. As seen in Table 5, there was not a significant difference in the change from baseline one and baseline two in GSR, respiration rate, or heart rate.

Table 5

Statistics for Baseline 1 and Baseline 2 on Arousal States $(N=76)$

\begin{tabular}{lccccccc}
\hline & Baseline 1 & \multicolumn{5}{c}{ Baseline 2 } \\
& Mean & SD & Mean & SD & $\mathrm{t}$ & $\mathrm{p}$ \\
\hline GSR & 1.299 & .742 & 1.252 & .799 & .97 & .33 \\
RESP & 14.728 & 3.443 & 14.831 & 3.707 & .30 & .77 \\
HR & 77.819 & 12.047 & 77.509 & 12.291 & .85 & .40 \\
\hline
\end{tabular}

Note: $\mathrm{df}=(1,74)$. 
In order to investigate the relationship between empathy and mood state, post hoc Pearson's correlations were conducted. As seen in Table 6, significant positive correlations were obtained for four of the five negative mood states. Thus, as in prior research, level of empathy was correlated with negative mood states that are commonly reported as symptoms of secondary trauma, and not significantly correlated with positive mood state.

Table 6

Correlations Between Empathy and Mood State $(N=76)$

\begin{tabular}{lllll}
\hline & Empathy & $\mathrm{p}$ & Mean & $\mathrm{SD}$ \\
\hline Empathy & ----- & ----- & 3.730 & .485 \\
$\mathrm{~T}$ & .318 & .005 & 55.145 & 11.744 \\
$\mathrm{D}$ & .287 & .012 & 49.342 & 8.233 \\
$\mathrm{~A}$ & .143 & .217 & 46.947 & 9.134 \\
$\mathrm{~F}$ & .345 & .002 & 46.566 & 7.767 \\
$\mathrm{C}$ & .245 & .033 & 51.026 & 8.624 \\
$\mathrm{~V}$ & -.103 & .376 & 35.829 & 6.531 \\
\hline
\end{tabular}

Note: $\mathrm{T}=$ Tension-Anxiety; $\mathrm{D}=$ Depression-Dejection; $\mathrm{A}=$ Anger-Hostility; $\mathrm{F}=$ FatigueInertia; $\mathrm{C}=$ Confusion-Bewilderment; $\mathrm{V}=$ Vigor-Activity.

Personality characteristics were also examined for exploratory purposes to determine if individuals with certain traits experienced higher arousal as a result of exposure to this media. Analyses indicated the absence of such a relationship on any of 
the "Big Five" personality characteristics. To better understand this data and possible relationship to empathy, a Pearson correlation was conducted across all five personality characteristics and empathy. As seen in Table 7, empathy was significantly correlated with all personality traits except conscientiousness. The magnitude of this relationship was small, and suggests that empathy is indeed a separate construct from the other measured personality traits.

Table 7

Pearson Correlations Between Empathy and Personality Characteristics $(N=76)$

\begin{tabular}{lllll}
\hline & Empathy & $\mathrm{p}$ & Mean & SD \\
\hline Empathy & ----- & ----- & 3.730 & .485 \\
$\mathrm{~N}$ & .299 & .009 & 2.776 & 1.066 \\
$\mathrm{E}$ & .298 & .009 & 2.395 & 1.008 \\
$\mathrm{O}$ & .345 & .002 & 3.145 & 1.029 \\
$\mathrm{~A}$ & .237 & .040 & 1.605 & 1.008 \\
$\mathrm{C}$ & -.213 & .065 & 1.421 & 1.223 \\
\hline
\end{tabular}

Note: $\mathrm{N}=$ Neuroticism; $\mathrm{E}=$ Extraversion; $\mathrm{O}=$ Openness to Experience; $\mathrm{A}=$ Agreeableness; $\mathrm{C}=$ Conscientiousness.

Further, post hoc Pearson's correlations were conducted to explore the relationship between age and physiological arousal at each baseline and the 911 emergency call condition. As seen in Table 8, there was an absence of any significant correlations between age and arousal state across all three conditions. 
Table 8

Pearson Correlations Between Age and Arousal in the 911 Emergency Call Condition and Baseline $(N=76)$

\begin{tabular}{|c|c|c|c|c|c|c|c|c|c|c|}
\hline & 1 & 2 & 3 & 4 & 5 & 6 & 7 & 8 & 9 & 10 \\
\hline 1. Age & - & -.067 & .010 & -.161 & -.211 & .037 & -.166 & -.138 & -.104 & -.176 \\
\hline 2. $911 \mathrm{GSR}$ & & - & -.175 & .110 & .767 & .086 & .159 & .918 & -.080 & .126 \\
\hline 3. 911 RESP & & & - & .186 & -.153 & -.199 & .495 & -.129 & .829 & .196 \\
\hline 4. $911 \mathrm{HR}$ & & & & - & -.033 & .155 & .951 & .104 & $.251 *$ & .980 \\
\hline 5. B1 GSR & & & & & - & .059 & .037 & .771 & -.144 & .003 \\
\hline 6. B1 RESP & & & & & & - & .178 & .064 & 649 & .152 \\
\hline 7. B1 HR & & & & & & & - & .135 & $.255^{*}$ & .966 \\
\hline 8. B2 GSR & & & & & & & & - & -.070 & .135 \\
\hline 9. B2 RESP & & & & & & & & & - & $.265 *$ \\
\hline 10. B2 HR & & & & & & & & & & - \\
\hline Mean & 26.99 & 1.13 & 17.01 & 78.12 & 1.30 & 14.73 & 77.82 & 1.25 & 14.83 & 77.51 \\
\hline SD & 4.45 & .76 & 4.34 & 12.18 & .74 & 3.44 & 12.05 & .78 & 3.71 & 12.29 \\
\hline
\end{tabular}

$* \mathrm{p}<.05,2$ tailed.

The relationship between age and score on psychological assessments in the battery were also examined using Pearson's correlations (See Table 9-10). Again, there was not a significant relationship observed between age and any measure of the psychological battery. 
Table 9

Pearson Product-Moment Correlations Between Age, Personality Characteristics, and Empathy $(N=76)$

\begin{tabular}{|c|c|c|c|c|c|c|c|}
\hline & $\mathrm{AGE}$ & $\mathrm{N}$ & $\mathrm{E}$ & $\mathrm{O}$ & A & $\mathrm{C}$ & EMP \\
\hline$\overline{\text { Age }}$ & - & .081 & .177 & .219 & -.007 & .212 & .049 \\
\hline $\mathrm{N}$ & & - & -.066 & -.055 & -.183 & $-.232 *$ & .299 \\
\hline $\mathrm{E}$ & & & - & .433 & .142 & .051 & .298 \\
\hline $\mathrm{O}$ & & & & - & .326 & -.030 & .345 \\
\hline A & & & & & - & -.016 & $.237 *$ \\
\hline $\mathrm{C}$ & & & & & & - & -.213 \\
\hline EMP & & & & & & & - \\
\hline Mean & 25.99 & 2.78 & 2.39 & 3.14 & 1.61 & 1.42 & 3.73 \\
\hline SD & 4.45 & 1.07 & 1.01 & 1.03 & 1.01 & 1.12 & .48 \\
\hline
\end{tabular}

Note: $\mathrm{N}=$ Neuroticism; $\mathrm{E}=$ Extraversion; $\mathrm{O}=$ Openness to Experience; $\mathrm{A}=$ Agreeableness;

$\mathrm{C}=$ Conscientiousness; Emp=Empathy.

$* \mathrm{p}<.05,2$ tailed. 
Table 10

Pearson Product-Moment Correlations Between Age, Mood, and PTSD Baseline (N=76)

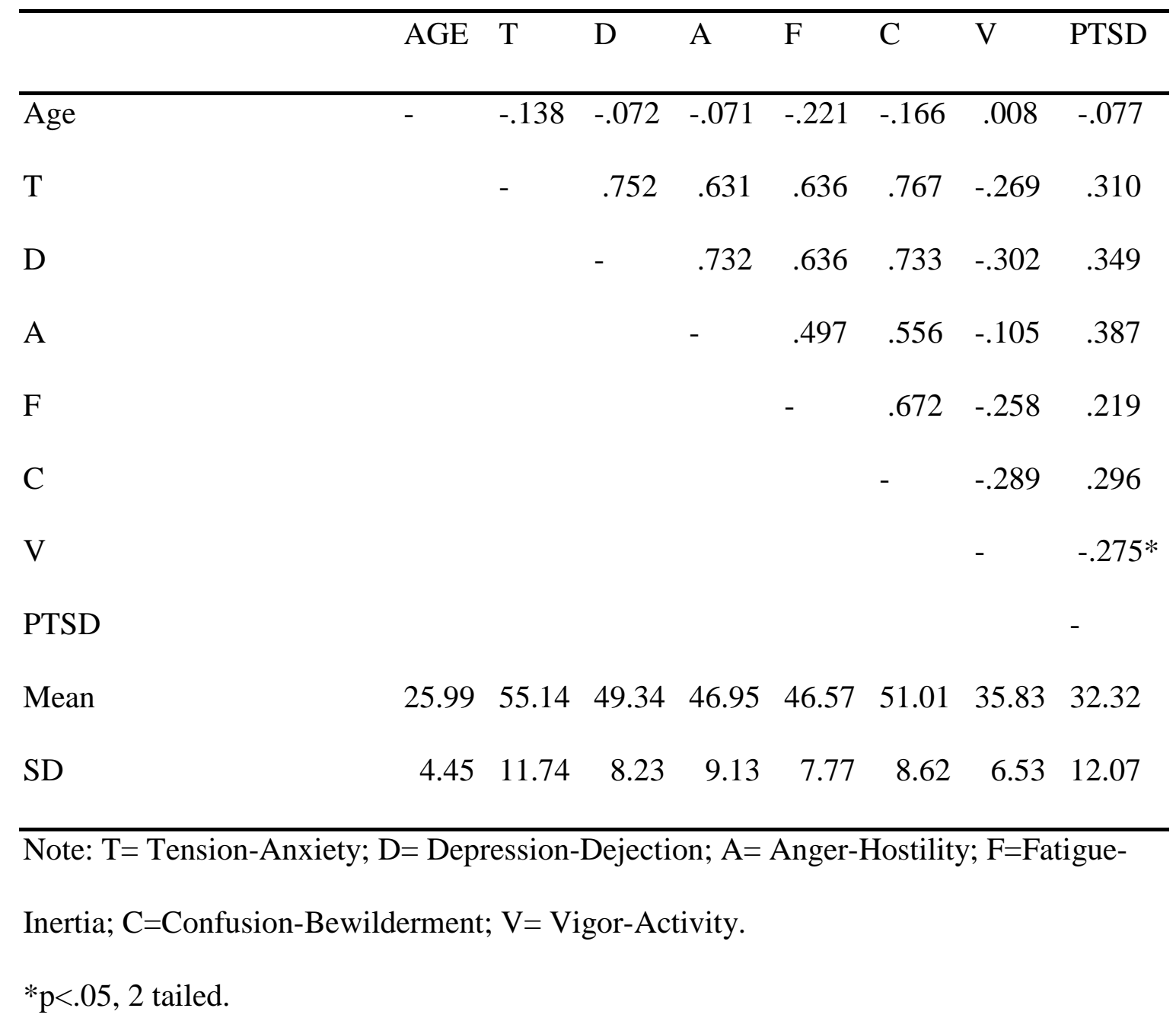

Further, the relationship between gender and arousal state along with scores on the psychological battery were examined utilizing an ANOVA to provide support for previous studies (Eidelson, D’Alessio \& Eidelson, 2003). Results indicated women $(\mathrm{M}=3.82, \mathrm{SD}=.48)$ scored higher then men $(\mathrm{M}=3.50, \mathrm{SD}=.42)$ on level of empathy, $\mathrm{F}$ $(1,74)=7.92, p=.006$. Differences in mood state were additionally analyzed using an ANOVA. Results indicated that women reported higher levels of Tension-Anxiety, 
Depression-Dejection, and Confusion-Bewilderment. Table 11 displays the associated statistics.

\section{Table 11}

Statistics for Mood State Along Gender (N=76)

\begin{tabular}{llllllll}
\hline Mood State & \multicolumn{2}{c}{ Male } & \multicolumn{3}{c}{ Female } & & \\
& $\mathrm{M}$ & $\mathrm{SD}$ & $\mathrm{M}$ & $\mathrm{SD}$ & $\mathrm{F}$ & $\mathrm{p}$ \\
\hline $\mathrm{T}$ & 49.095 & 8.508 & 57.455 & 12.044 & 8.47 & $.005^{*}$ \\
$\mathrm{D}$ & 45.191 & 5.269 & 50.927 & 8.636 & 8.08 & $.006^{*}$ \\
$\mathrm{~A}$ & 44.857 & 6.901 & 47.746 & 9.793 & 1.53 & .220 \\
$\mathrm{~F}$ & 44.952 & 7.691 & 47.182 & 7.777 & 1.26 & .266 \\
$\mathrm{C}$ & 46.952 & 3.735 & 52.582 & 9.445 & 6.99 & $.010^{*}$ \\
$\mathrm{~V}$ & 37.714 & 7.100 & 35.109 & 6.217 & 2.47 & .121 \\
\hline
\end{tabular}

Note: $\mathrm{T}=$ Tension-Anxiety; $\mathrm{D}=$ Depression-Dejection; A= Anger-Hostility; F=FatigueInertia; $\mathrm{C}=$ Confusion-Bewilderment; $\mathrm{V}=$ Vigor-Activity.

$* \mathrm{df}=(1,74), \mathrm{p}<.05,2$ tailed.

Finally, differences in arousal due to gender at baseline and the 911 emergency phone call condition were examined utilizing an ANOVA. A significant difference was observed at initial baseline in terms of respiration rate and heart rate; women yielded higher levels then men. Additionally at baseline two, women continued to display higher levels of respiration and heart rate. This same difference was also observed during the 
911emergency phone call condition, in which women displayed higher levels of both respiration rate (See Table 12).

Table 12

Statistics for Arousal at Baseline and 911 Emergency Phone Call Condition Along

Gender $(N=76)$

\begin{tabular}{|c|c|c|c|c|c|c|}
\hline \multirow[t]{2}{*}{ Arousal } & \multicolumn{2}{|c|}{ Male } & \multicolumn{2}{|c|}{ Female } & \multirow[b]{2}{*}{$\mathrm{F}$} & \multirow[b]{2}{*}{$\mathrm{p}$} \\
\hline & $\mathrm{M}$ & SD & $\mathrm{M}$ & $\mathrm{SD}$ & & \\
\hline B1 GSR & 1.390 & .663 & 1.265 & .773 & .430 & .514 \\
\hline B1 RESP & 13.162 & 3.237 & 15.326 & 3.356 & 6.44 & $.001 *$ \\
\hline B1 HR & 72.351 & 9.569 & 79.907 & 12.312 & 6.41 & $.013 *$ \\
\hline B2 GSR & 1.249 & .673 & 1.253 & .849 & .001 & .982 \\
\hline B2 RESP & 12.648 & 3.292 & 15.666 & 3.537 & 11.48 & $.001 *$ \\
\hline B2 HR & 71.662 & 9.741 & 79.742 & 12.502 & 7.10 & $.009 *$ \\
\hline 911 GSR & 1.233 & .577 & 1.094 & .818 & .507 & .479 \\
\hline 911 RESP & 14.749 & 4.629 & 17.940 & 3.924 & 9.09 & $.004^{*}$ \\
\hline $911 \mathrm{HR}$ & 72.916 & 9.574 & 80.109 & 12.550 & 5.63 & $.020 *$ \\
\hline
\end{tabular}

Note: $\mathrm{p}<.05, \mathrm{df}=(1,74)$

\section{Chapter V}

\section{Discussion}

The purpose of the study was to investigate the relationship between physiological and psychological arousal in response to 911 emergency phone calls and the difference of this response compared to news coverage of identical stories. In support 
of hypothesis one, results indicated that overall, participants displayed higher levels of arousal in the 911 condition compared to news reports according to GSR and respiration rate. Closer analyses in the 911 emergency phone call condition showed respiration rate and negative mood states were positively correlated with each other, while neither GSR nor heart rate were related to mood. The nature of this relationship indicated that as participants reported higher levels of negative moods in the 911 condition, their rate of respiration increased; these results failed to support all the components of hypothesis two. To better understand how personality characteristics related with arousal, five traits and empathy were examined while controlling for the influence of age and gender on arousal. Again, analyses did not support that the six variables influenced the level of arousal on any of the three modalities during exposure to the 911 emergency call condition. The results failed to support hypothesis three that a significant relationship existed between personality and arousal. Finally, participants' baseline level of PTSD was correlated with respiration rate in the 911 emergency call condition. This relationship identified that those who reported higher levels of PTSD produced higher levels of respiration in the 911 emergency call condition. GSR and heart rate were not correlated with PTSD score, and thus the final hypothesis was not fully supported.

Post hoc analyses were conducted to examine the presence of Seyle's adaptation model in response to the 911 emergency call condition. Arousal across the three modalities was compared across the two baselines to determine if arousal was sustained. An absence of arousal was observed at baseline two, thus failing to support this theory, the absence of continued arousal in this experiment may be a reflection of the lack of magnitude in arousal as a result of the 911 emergency call condition. Thus, indicating 
that participants were mildly aroused, which was not enough to activate the fight or flight response, and as a result levels of hyperarousal were not obtained, therefore not sustained. These findings suggest an indifferent or perhaps a conditioned response to such media.

Post hoc correlations were conducted to examine the relationship between empathy and mood states which was not encompassed in the original hypotheses. Significant relationships were obtained for the negative mood states, and not the positive mood state. This finding parallels previous research that addresses topics of secondary trauma; the negative mood states assessed by the POMS are common mood states experienced in those with PTSD or a secondary trauma response. Thus, as anticipated individuals who report higher levels of emotional connection with others, may have practiced this identification with victims in the news reports and the change in mood may have been moderated by the strength of this relationship. These correlations also lacked significance in regards to positive mood state, which was again expected indicating that people with high levels of empathy did not report positive changes in mood after viewing such media.

The relationship between personality characteristics and arousal was also examined to determine if individuals with certain personality profiles responded in a differential manner to the 911 emergency call condition. Results failed to support the presence of any relationship between personality characteristics and arousal, revealing that people regardless of their personalities respond to the media in a very similar manner. Further the relationship between age and physiological arousal as well as psychological arousal was explored to determine differences in certain ranges. There was 
an absence of any significant correlation between age and arousal, further reveling that people responded in a similar manner across the lifespan. Finally, post hoc exploratory analyses focused on the relationship between gender and arousal state. Women reported higher levels of empathy, tension-anxiety, depression-dejection and confusionbewilderment. Differences were also identified between women and men in terms of physiological arousal; women yelled higher levels of respiration and heart rate. The driving forces behind such differences due to gender are unknown and may be a reflection of socialization of women in regards to empathy and an emphasis on caring for other sin our society. Additionally higher levels of interference in mood may also be a reflection of women openly discussion and reporting change in mood as opposed to their male counterparts.

\section{Limitations of the Study}

The presence of a variety of limitations must be acknowledged for future research and interpretations of this study. Given the nature of the participant population, aspects of age, gender, and educational level must be noted for impact on external validity. The sample was comprised mainly of young women who were full-time graduate students in a clinical psychology program. Given the field of their education, this sample may additionally have reported higher than average levels of empathy, thus impacting the significance of results when including this variable. Furthermore, given that the students attended a private university, they are more likely to identify with a higher socioeconomic group and have more access to educational opportunities and experiences which may impact their perception and experience of threatening or traumatic stimuli. As a result of these factors, the results of this study may not reflect the general population. 
The study included individuals with an age range of 18 to 44 years old. Given this span, there are many limitations to consider that would influence both psychological and physiological arousal states. Considering age, the sample was less likely to have serious chronic medical conditions (e.g. heart disease, diabetes, hypertension) that may impact their response to the stimuli. Additionally, as a social cohort in the United States, these individuals may have more exposure to such stimuli given the amount of exposure to a variety of media that would not be found in an older population or children. Thus, just considering general exposure levels there may be the presence of a conditioned response to the 911 emergency phone call tapes and traumatic stories in the media, limiting the magnitude of the observed response. The general population may not have access or limited access to such media, and an increased presence of general medical conditions that would influence physiological response.

A further limitation of this study was the use of a psychological battery that did not include a measure of change in cognition as a result of exposure. Previous research has linked the altercation of cognition and underlying schemas of safety to feelings of arousal after exposure to a threatening or traumatic stimulus, and the absence of such a measure was an oversight by the primary investigator. Additionally, the current study failed to assess hours of television viewed on a daily basis. The amount of hours viewed may mediate the intensity of response as observed in previous studies (Fallahi \& Lesik, 2009; Propper, Strickgold, Keeley \& Chrisman, 2007).

Furthermore, the BioTrace biofeedback equipment utilized is designed to eliminate human error, however on a variety of occasions the sensors would loose connectivity or fail to record any physiological output. At one point in the study, new 
GSR sensors were required to be purchased as a result of instrumentation failure and data was lost for participants. The new sensors may have been more accurate than the previously employed hardware. The company indicates medical grade standards of their sensors at time of production as a means to eliminate human error, yet after duration of use, the accuracy of sensors may have declined.

The investigation additionally suffers from the lack of inter-rater reliability given that the primary researcher conducted all participant trials in the lab. Although, following adherence to a strict procedural protocol the impact that the administrator had on participants and the presence of any desirability effect in performance was not controlled. Additionally, participants were provided with fifteen dollars in compensation for their time, impacting their response set in an undetermined manner.

Finally, the investigation itself may have been arousing to individuals, and the absence of a control group that was merely exposed to the biofeedback hardware and a neutral audio condition was not included in the study design. The presence of such a group would allow for determining the magnitude of impact the experimental condition caused on arousal levels, yet the lab was a standard therapy room with two chairs, desk, lamp, and a computer, and otherwise absent of novel stimuli. The nature of the setting was not considered to be markedly foreign by the primary investigator and it was assumed to have minimal impact of the assessed variables. In line with environmental influence, participants were scheduled in the lab at a variety of hours from 9:00AM to 6:00PM throughout the week to best correspond with participant availability. Aspects of difference in physiological arousal states across the day were not considered, and may have impacted the results. In attempts to standardize the procedure, future administration 
may want to transpire during a certain hour range and factor this into statistical analysis as a possible mediating variable.

\section{Findings Relative to Previous Research}

The current study's findings are consistent with Cannon's fight or flight theory in terms of higher arousal in the 911 phone call condition versus simple news reports. Interestingly, this difference was not achieved on all three levels of measure, with heart rate not exhibiting a significant variance. The reasons for a lack of increase in heart rate remain undetermined and may be the result of the lack of severity of traumatic value innate to the audio recordings. Given that such stimuli are representations of normal daily exposure, the nature of the reports may have lacked the shock value required to activate the arousal as predicted by Cannon's theory.

Regarding Seyle's adaptation theory, post hoc analysis was conducted examining the difference in arousal states from initial baseline to post exposure baseline to determine if individuals were able to obtain a reduction in arousal. Again, three paired t tests were performed to compare the means of each arousal state across the two conditions. There was not a significant difference in the change of microvolts, respiration, or heart rate. Closer examination of the means highlight no unit change across baselines, thus failing to fall in accordance to Seyle's adaptation theory. Again, the absence of continued arousal in this experiment may be a reflection of the lack of magnitude in arousal as a result of the 911 emergency call condition. Thus, indicating that participants were mildly aroused, which was not enough to activate significant flight or fight reactions, and as a result levels of hyperarousal were not obtained, therefore not sustained. These findings suggest an indifferent or perhaps indicate the presence of a 
conditioned response to the nature of such media. Given the nature of the 911 calls (e.g. car accident, shooting, death of child) the lack of significant differences is concerning to this investigator, and may be an indication of lack of social connectedness or empathy for others.

In terms of empathy, counter to previous studies (Dirkzwager et al., 2005; McCann \& Perlman, 1990), individuals who reported elevated levels did not display higher arousal in the 911 phone call condition. Empathy, or "the action of understanding, being aware of, being sensitive to, and vicariously experiencing the feelings, thoughts, and experience of another... without having the feelings, thoughts, and experience fully communicated in an objectively explicit manner" (empathy, Merriam-Webster, 2012) has also previously been considered to be a protective mechanism (Carmel \& Friedlander, 2009; Figley, 1995; Harrison \& Westwood, 2009) in which individuals have reported feeling invigorated as a result of this connection with others. In order to investigate the relationship between empathy and mood state, post hoc Pearson correlations were conducted. In two cases, Tension-Anxiety $[\mathrm{r}(76)=.32, \mathrm{p}<.05]$ and Fatigue-Inertia $[\mathrm{r}$ $(76)=.35, \mathrm{p}<.05]$ significant correlations were obtained, indicating a positive linear relationship between these mood states and level of empathy. Thus, as in prior research, level of empathy was correlated with negative mood states that are commonly reported as symptoms of secondary trauma, and more importantly not significantly correlated with positive mood state $[\mathrm{r}(76)=-.10, \mathrm{p}>.05]$. Applying the concept of secondary trauma, with emphasis on the empathetic component, prior research findings were not supported (Eidelson \& colleagues, 2003; Figley, 1995; Harrison \& Westwood, 2009; McCann \& Perlman, 1990). This study did not employ a measure to assess the cognitive change in 
belief systems as a result of exposure and can offer no support for prior research that indicates a change in cognitive schemas and world belief as a result of exposure to traumatic stimuli (Brady, Guy, Poelstra \& Brokaw, 1999; Bober \& Regehr, 2006; Dougall, Hayward \& Baum, 2005; Huesmann, Moise-Titus, Podolski \& Eron, 2003; McCann \& Pearlman, 1990; Propper, Strickgold, Keeley \& Chrisman, 2007).

Personality characteristics were then examined for exploratory purposes to determine if individuals with certain traits are at higher risk for experiencing arousal as a result of exposure to a traumatic stimulus. Analyses indicated the absence of such a relationship on any of the "Big Five" personality characteristics. A closer look at trends in the data suggested that individuals with higher levels of contentiousness displayed higher levels of heart rate and microvolts in the 911 condition compared to the news condition. Additionally, individuals with higher levels of Neuroticism displayed higher levels of respiration in the 911 condition. To better understand the trends in this data and possible relationship to empathy, a Pearson correlation was conducted across all five personality characteristics and empathy (See Table 6). Furthermore, there was a significant positive correlation between empathy and neuroticism, extraversion, and openness to experience, yet these intercorrelations did not influence the level of arousal to a significant degree.

Furthermore, demographic characteristics of gender and age were not considered in the original hypotheses as significant variables on arousal state in the 911 emergency condition or across the psychological battery, as found in previous research (Bober \& Regehr, 2006). Post-hoc Pearson correlations were conducted to explore the presence of a linear relationship between age on physiological arousal, both at baseline and the 911 
emergency call condition (See Table 7). Results highlight the absence of any significant correlations between age and arousal state, both at baseline and during the arousal condition, as well as age and score on psychological measures (See Table 8-Table 9). Additionally, the relationship between gender and arousal state along with reports on the psychological battery were examined utilizing an ANOVA to provide support for previous studies (Eidelson, D’Alessio \& Eidelson, 2003). Results indicated women scored higher then men in regards to level of empathy $[F(1,74)=7.92, p<.05]$. Additionally, women reported higher levels of Tension-Anxiety, Depression-Dejection, and Confusion-Bewilderment (See Table 11). Finally, differences in arousal due to gender at baseline and the 911 emergency phone call condition were examined utilizing another ANOVA. Results highlighted a significant difference at baseline in terms of respiration rate and heart rate: women yielded higher levels then men. Additionally, the same difference was observed in the 911 emergency phone call condition in which women displayed higher levels of respiration and higher heart rate (See Table 12).

\section{Implications for Practice and Future Research}

Future research is required to further understand the impact that exposure to 911 emergency recordings have on psychological and physiological arousal. To better understand arousal, additional biological tests may be administered pre and post exposure such as a saliva swab to monitor cortisol levels as an indication of stress and measure activity of the HPA axis. This data would allow researchers to make broader conclusions regarding impact on overall health due to cortisol impact on inflammation and exacerbation of a variety of conditions. Furthermore, the addition of a simple blood test to measure cortisol levels, natural killer cells, and inflammatory hormones would provide 
insight if such stimuli is consider to be time limited or chronic in nature (Segerstrom \& Miller, 2004). Such tests would assist in the establishment of identifying clear physiological ranges that are indicative of a secondary trauma response, and help to identify individuals at risk for developing more serious psychopathology or medical complications.

The influence of empathy on arousal in response to traumatic stimuli has mixed results in the literature. Further investigation into the protective aspects of this emotional construct versus risks should be explored to better understand the nature of this variable. The utilization of a variety of instruments to assess different components of empathy (e.g., feeling for others, easily crying, emotional attention) may be employed for clarification purposes. Additionally, qualitative surveys that directly address the level of empathetic engagement with the media as opposed to passive consumption may be utilized for further clarification of this relationship. This information will not only provide a better understanding of the role of empathy, but highlight the presence of conditioning to such media, or identify that individuals simply have no acknowledgement and response to such forms of human suffering.

As noted in the discussion of weakness innate to the current study, future research should encompass aspects of cognitive change in response to this form of media (Nixon $\&$ Nishith, 2005). Changes in worldview, safety, perceived threat, or anxiety may be explored to discover the presence of a negative thought bias post exposure to 911 emergency phone calls. In line with cognitive theory, such changes if present have large implications on emotional health and behavior and may result in the exacerbation of secondary trauma symptoms such as depression or anxiety, and a decrease in pro-social 
or altruistic behavior. Furthermore, identifying the nature of which 911 emergency calls have the most impact on physiological arousal is important to understand which media is most damaging. Previous research (Brady, 1999) has indicated a differential response in intensity attributed to the level of violence in the media (e.g., intent to kill versus natural disaster). Clarification of the most threatening media may provide broadcasting corporations with the option of selecting to remove all media of a specific nature (e.g., death of a child) as opposed to all recordings. Additionally, the absence of assessing average hours of television viewed further hinders the understanding that exposure may have on intensity of arousal, or aspects of a conditioning response, and future research thus should aim to clarify this process.

Finally, the utilization of a larger sample in terms of age, gender, and level of education is important to obtain a more accurate synopsis of how the general public in the United States responds to the media. Other countries have conducted such investigations, in particular whose media is marked by a high volume of traumatic stimuli, and identified both an increase in depression and anxiety, but at other times an aspect of desensitization. Recordings of this nature are rather new to the media in the United States, and culturally there may be a differential response on both a physiological and psychological levels, with effects that remain unknown on both the individual and societal level. 


\section{References}

Adams, S., \& Riggs, S. (2008). An exploratory study of vicarious trauma among therapist trainees. Training and Education in Professional Psychology, 2, 26-34.

Ahern, J., Galea, S., Resnick, H., Kilpatrick, D., Bucuvalas, M., Gold, J., Vlahov, D., Galea, S. (2002). Television images and psychological symptoms after the September 11 terrorist attacks, Psychiatry: Interpersonal and Biological Process, $65,4,289-300$.

Baker, L., \& Taylor, W. (1954). The relationship under stress between changes in skin temperature, electrical skin resistance, and pulse rate. Journal of Experimental Psychology, 5, 361-366.

Batten, S., \& Orsillo, S. (2002). Therapist reactions in the context of collective trauma. The Behavior Therapist, 25, 36-38.

Bober, T., \& Regehr, C. (2006). Strategies for reducing secondary or vicarious trauma: Do they work. Brief Treatment and Crisis Intervention, 6, 1-9.

Boris, N., Byrne, C., Diaz, E., \& Kaniasty, K. (2001). The mental health consequence of terrorism: implications for emergency medicine practitioners. The Journal of Emergency Medicine, 32, 139-147.

Boyse, K., \& Bushman, B. (2010). Television and your children: University of Michigan Health System, retrieved http://www.med.umich.edu/yourchild/topics/tv

Brady, J., Guy, J., Poelstra, P., \& Brokaw, F. (1999). Vicarious traumatization, spirituality, and the treatment of sexual abuse survivors: A national survey of women psychotherapists. Professional Psychology: Research and Practice, 4, 386-393. 
Braun-Lewensohn, O., Clestin-Westreich, S., Celestin, L., Verte, D., \& PonjaertKristoffersen, I. (2009). Adolescent's mental health outcomes according to different types of exposure to ongoing terror attacks. Journal of Youth and Adolescence, 38, 850-862.

Bushman, B., \& Anderson, C. (2001). Media violence and the American public: Scientific facts versus media misinformation. American Psychologist, 56, 477489.

Bushman, B., \& Anderson, C. (2009). Comfortably numb: Desensitizing effects of violent media on helping others. Psychological Science, 21, 3, 273-277.

Cannon, W. (1915). Bodily Changes in Pain, Hunger, Fear and Rage: An Account of Recent Researches into the Function of Emotional Excitement, Appleton, New York.

Carmel, M., Friedlander, M. (2009). The relation of secondary traumatization to therapists' perception of the working alliance with clients who commit sexual abuse. Journal of Counseling Psychology, 56, 461-467.

Caruso, D., \& Mayer, J. (1998). A measure of emotional empathy for adolescents and adults. Unpublished manuscript.

Cho, J., Boyle, M., Keum, H., Shevy, M., McLeod, D., et al. (2003). Media, terrorism, and emotionality: Emotional differences in media content and public reactions to the September $11^{\text {th }}$ terrorist attacks. Journal of Broadcasting \& Electric Media, $47,3,309-327$.

Costa, P., \& McCrae, R. (1992). NEO PI-R professional manual. Odessa, Fl Psychological Assessment Resources, Inc. 
Coyne, S., Nelson, D., Laton, F., Haslam, S., Rooney, L., Titterington, L., Trainor, H., Remnant, J., \& Ogunlaja, L. (2005). The effects of viewing physical and relational aggression in the media: Evidence for a cross-over effect. Journal of Experimental Social Psychology, 44, 6, 1551-1554.

Dirkzwager, A., Bramsen, I., Ader, H., \& van der Ploeg, H. (2005). Secondary traumatization in partners and parents of Dutch peacekeeping soldiers. Journal of Family Psychology, 19, 217-226.

Dougall, A., Hayward, M., Baum, A. 92005). Media exposure to bioterrorism: Stress and the anthrax attacks. Psychiatry, 68, 28- 42.

Eidelson, R., D’Alessio, G., \& Eidelson, J. (2003). The impact of September 11 on Psychologists. Professional Psychology: Research and Practice, 2, 144-150.

Empathy. (2012). In Merriam- Webster.com. Retrieved March 9, 2012, from http://www.merriam-webster.com/dictionary/empathy.

Fallahi, C., \& Lesik, S. (2009). The effects of vicarious exposure to the recent massacre t Virginia Tech. Psychological Trauma: Theory, Research, Practice, and Policy, 3, 220-230.

Fals-Stewart, W., \& Kelley, M. (2005). When family members go to war- A systemic perspective on harm and healing: Comment on Dirkzwager, Bramsen, Ader, and van der Ploeg (2005). Journal of Family Psychology, 2, 233-236.

Figley, C. (1995). Compassion fatigue: Coping with secondary traumatic stress disorder in those who treat the traumatized. Bristol, PA: Brunner/Mazel.

Frasure-Smith, N. \& Lesperance, F. (2005). Reflections on depression as a cardiac risk factor. Psychosomatic Medicine, 67, 519-525. 
Glasser, R. \& Godbout, J. (2006). Stress-induced immune dysregulation for wound healing, infectious disease and cancer. Journal of Neuroimmune Pharmacology, 1, 421-427.

Harrison, R., \& Westwood, M. (2009). Preventing vicarious traumatization of mental health therapists: Identifying protective practices. Psychotherapy Theory, Research, Practice, Training, 2, 203-219.

Herman, J. (1997). Trauma and recovery. New York: Basic Books.

Hoven, H., Duarte, C., Lucas, C., Mandell, D., Wu, P., Rosen, C. (2002). Effects of the world trade center attack on New York City public school students. Initial report to the New York City public Board of Education. New York: Applied Research and Consulting, LLC, Columbia University Mailman School of Public Health, New York State Psychiatric Institute.

Huesmann, L., Moise-Titus, J., Podolski, C., \& Eron, L. (2003). Longitudinal relations between children's exposure to TV violence and their aggressive and violent behavior in young adulthood. Developmental Psychology, 39, 2, 210-221.

Johnson, J., Cohen, P., Smalies, E., Kasen, S., \& Brook, J. (2002). Television viewing and aggressive behavior during adolescence and adulthood. Science, 295 $(2468-2471)$.

Joint statement on the impact of entertainment violence on children: Congressional Public Health Summit. Retrieved December 4, 2000 from the World Wide Web: http://www.senate.gov/b rownback/media_violence.html

Jordan, A., Hersey, J., McDivitt, J., Heitzler, C. (2006). Reducing children's television- 
viewing time: A qualitative study of parents and their children. Pediatrics, 118, 5, 1303-1310.

Jordan, B., Marmar, C., Fairbank, J., Schlenger, W., Kulka, R., Hough, R., et al. (1992). Problems in families of male Vietnam veterans with posttraumatic stress disorder. Journal of Consulting and Clinical Psychology, 60, 916-926.

Kendall-Tackett, K. (2009). Psychological trauma and physical health: A psychoneuroimmunology approach to etiology of negative health effects and possible interventions. Psychological Trauma: Theory, research, Practice and Policy, 1, 35-48.

Koplewica, H., Vogal, J., Solanto, M., Morrissey, R., Alonso, C., Abikoff, H., Gallagher, R., Novick, R. (2002). Child and parent response to the 1993 World Trade Center bombing. Journal of Traumatic Stress, 15, 77-85.

Laufer, A., \& Solomon, Z. (2003). Coping of Israeli children with the events of terror. The role of stressful events. In M. Caspis (Ed.), Children's anxiety as a result of the terror events (pp.4-7). Jerusalem: Israeli Knesset, research and information center.

Lawyer, S., Resnick, H., Galea, S., Ahern, J., Kilpatrick, D. \& Vlahov, D. (2006). Predictors of peritraumatic reactions and PTSD following the September $11^{\text {th }}$ terrorist attacks. Psychiatry- Interpersonal and Biological Processes, 69, 130-141.

McCann, L. \& Perlman, L. (1990). Vicarious traumatization: A framework for understanding the psychological effects of working with victims, Journal of Traumatic Stress, 3, 1, 131-149.

McNair, D., Lorr, M., \& Droppleman L. (1971). Manual for the profile of mood states. 
San Diego, CA: Educational and Industrial Testing Service

MindMedia B.V. (2004-2008). The Physiological Monitoring \& Biofeedback Company

Nader, K., Pynoos, R., Fairbans, L., Al-Ajeel, M., \& Al-Asfour, A. (1993). A preliminary study of PTSD and grief among the children of Kuwait following the Gulf crisis. British Journal of Clinical Psychology, 32, 407-416.

Nielsen Media Research Company. (2010). Television Measurement, obtained at http://neilsen.com/us/en/measurement/television-measurement.

Nixon, R., \& Nishith, P. (2005). September $11^{\text {th }}$ attacks: Prior interpersonal trauma, dysfunctional cognitions, and trauma response in a Midwestern university sample. Violence and Victims, 20, 471-480.

Ofman, P., Mastria, M., \& Steinberg, J. (1995). Mental health response to terrorism: The world trade center bombing. Journal of Mental Health Counseling, 17, 312-320.

Ohme, R., Reykowska, D., Wiener, D., \& Choromanska, A. (2009). Analysis of neurophysiological reactions to aversive stimuli by means of EEG and galvanic skin response measures. Journal of Neuroscience, Psychology, and Emotions, 2, 21-31.

Pace, T., Hu, F., \& Miller, A. (2007). Cytokine-effects on glucocorticoid receptor function: relevance to glucocorticoid resistance and the pathophysiology and treatment of major depression. Brain, Behavior and Immunology, 1, 9-19.

Pearlman, L. A., \& Saakvitne, K. W. (1995). Trauma and the therapist:

Countertransference and vicarious traumatization in psychotherapy with incest survivors. New York: Norton \& Company.

Pfefferbaum,B. (2001). The impact of the Oklahoma City bombing on children in the 
community. Military Medicine, 166, 12, 49-50.

Pfefferbaum, B., Doughty, D., Reddy, C., Patel, N., Gurwitch, R., Nixon, S., \& Tivis, R. (2002). Exposure and peritraumatic response as predictors of posttraumatic stress in children following the 1995 Oklahoma City bombing. Journal of Urban Health, 79, 3, 354-363.

Pfefferbaum, B., Nixon, S., Tivis, R., Doughty, D., Pynoos, R., Gurwitch, R., \& Foy, D. (2001). Television exposure in children after a terrorist incident. Psychiatry, 64, 202- 211.

Pfefferbaum, B., Seale, T., Brandt, E., Pfefferbaum, R., Doughty, D., \& Rainwater, S. (2003). Media exposure in children one hundred miles from a terrorist bombing. Analysis of Clinical Psychiatry, 15, 1-8.

Pfefferbaum. B., Seale, T., McDonald, N., Brandt, E., Rainwater, S., Maynard, B., Meierhoefer, B., \& Miller, P. (2000). Posttraumatic stress two years after the Oklahoma City bombing in youths geographically distant from the explosion. Psychiatry, 63, 358-370.

Propper, R., Strickgold, R., Keeley, R., \& Chrisman, S. (2007). Is television traumatic? Dreams, stress and media exposure in the aftermath of September 11, 2001. Psychological Science, 18, 4, 334-340.

Raber, J. (1998). Detrimental effects of chronic hypothalamic-pituitary-adrenal axis activation: From obesity to memory deficits. Molecular Neurobiology, 18, 1, 1-22

Schiff, M., \& Katz, K. (2007). Therapeutic components and differential treatment outcomes among clients of Israeli services for substance abusers. Social Work and Practice, 17, 1, 19-29. 
Segerstrom, S., \& Miller, G. (2004). Psychological stress and the human immune system: A meta-analysis study of 30 years of inquiry. Psychological Bulletin, 4, 601-630.

Senate Committee on the Judiciary. Children, violence ad the media: A report for parents and policy makers. September 14, 1999. Previously available at http://judiciary.senate.gov

Selye, H. (1956). The stress of life, New York: McGraw-Hill.

Slone, M., \& Shoshani, A. (2008). Indirect victimization from terrorism: A proposed post-exposure intervention. Journal of Mental Health counseling, 30, 255- 266.

Solomon, Z., Shklar, R. \& Mikulincer, M. (2005). Frontline treatment of combat stress reaction: A 20 year longitudinal evaluation study. American Journal of Psychiatry, 162, 2309-2314.

Solomon, Z., Waysman, M., Levy, G., Fried, B., Mikolincer, M., Benbenishty, R, Florian, V., \& Bleich, A. (1992). From front line to home front: A study of secondary traumatization. Family Process, 31, 289-301.

Sontag, S. (2005). Regarding the pain of others, Ben-Shemen, Israel: Modan Publishers.

Surtees, P., Wainwright, N., Luben, R., Wareham, N., Bingham, S., Khaw, K. (2008). Depression and ischemic heart disease mortality: evidence from the EPICNorfolk United Kingdom prospective cohort study, The American Journal of Psychiatry, 165, 515-523.

Terr, L., Bloch, D., Michel, B., Shi, H., Reinhardt, J., Metayer, S. (1999). Children's 
symptoms in the wake of the Challenger: A field study of distant-traumatic effects and an outline of related conditions. American Journal of Psychiatry, 156, 15361544.

United States Department of Labor. (2010). Economic News Release: American Times use Survey, obtained at http://www.bls.gov

Weathers, F., Litz, B., Herman, D., Huska, J., \& Keane, T. (1993) The PTSD checklist: Reliability, Validity, and Diagnostic Utility. Paper presented at the Annual Convention of the International society for Traumatic Stress Studies, San Antonio, TX. 


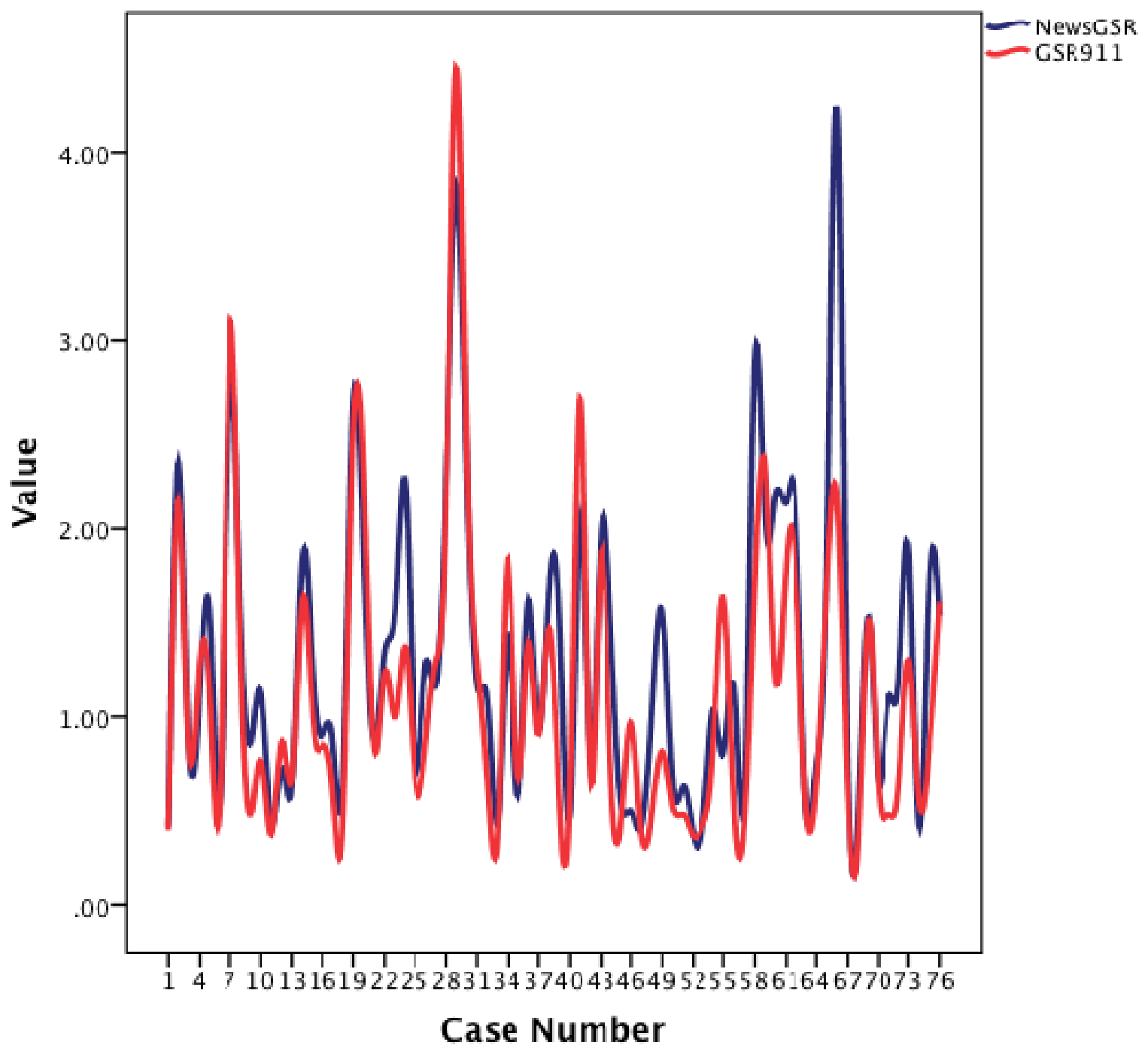

Figure 1:GSR Across Conditions 


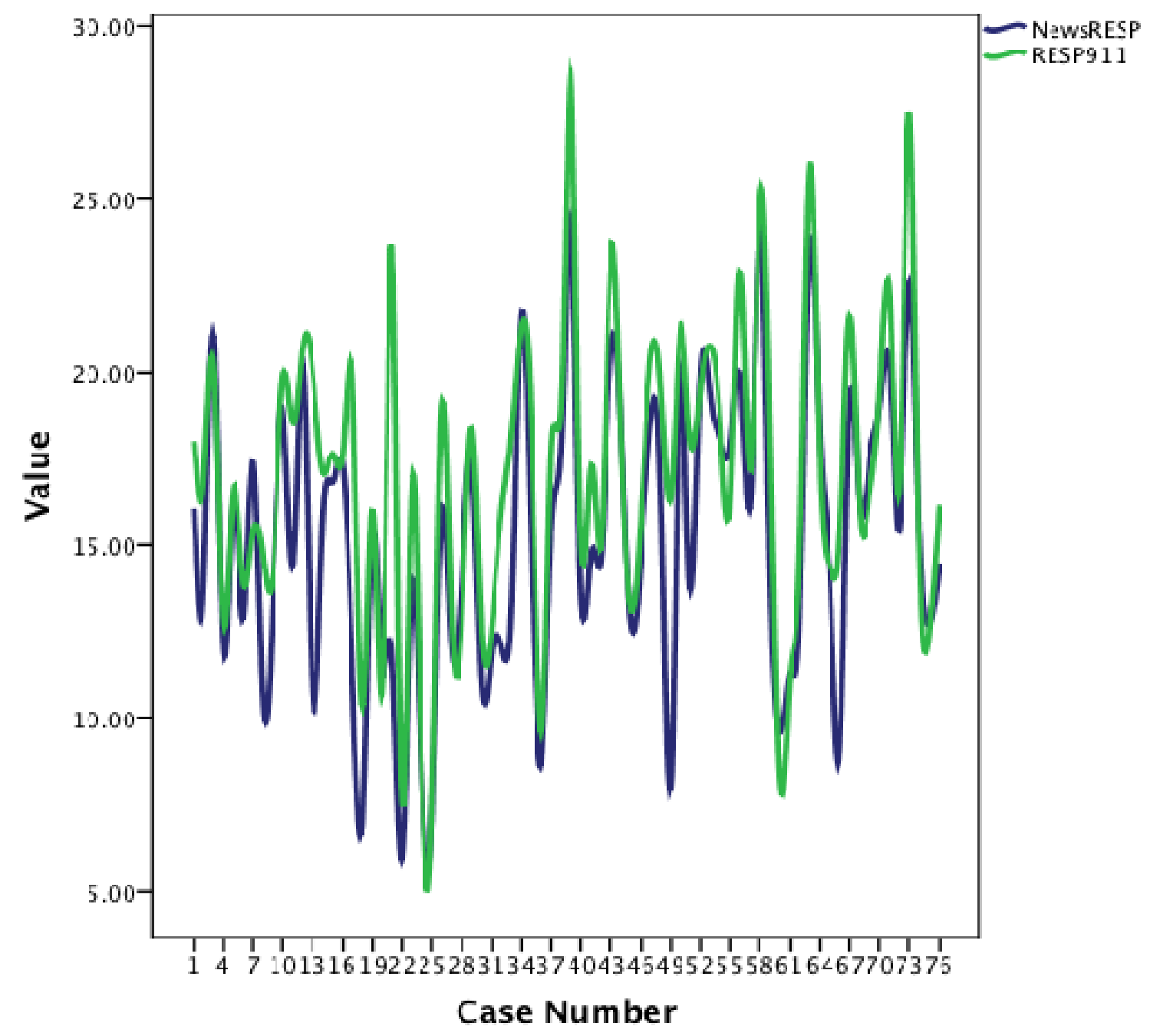

Figure 2: Respiration Rate Across Conditions 


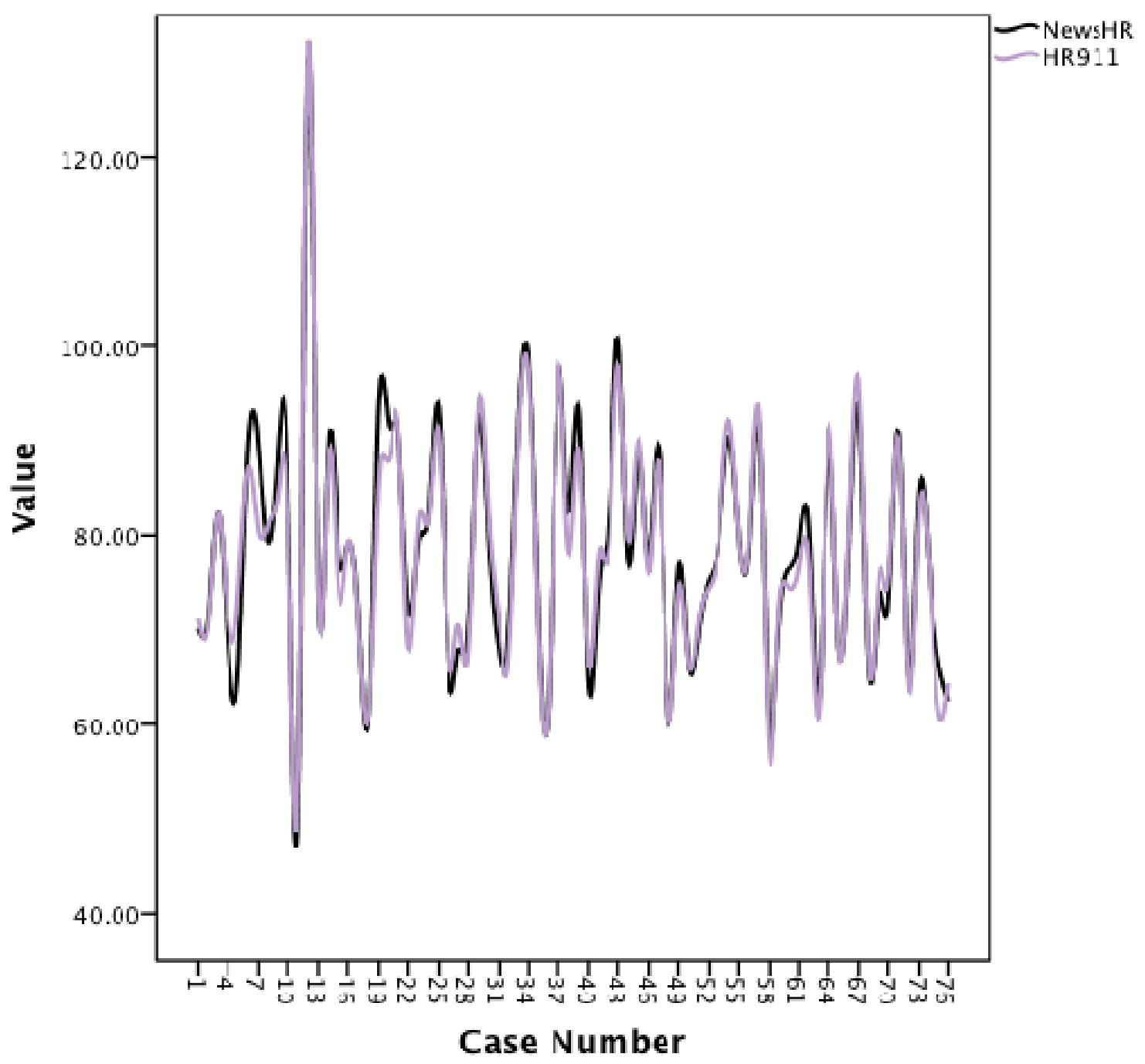

Figure 3: Heart Rate Across Conditions 


\section{Appendix A}

\section{Profile of Mood States}

Directions: Below is a list of words that describe feelings people have. Please read each one carefully, then circle the answer which best describes how you have been feelings RIGHT NOW.

The numbers refer to these phrases:

$$
\begin{aligned}
& 0=\text { Not at all } \\
& 1=\text { A little } \\
& 2=\text { Moderately } \\
& 3=\text { Quite a bit } \\
& 4=\text { Extremely }
\end{aligned}
$$

1. Friendly

2. Tense

3. Angry

4. Worn Out

5. Unhappy

6. Clear Headed

7. Lively

8. Confused

9. Sorry for things done

10. Shaky

11. Listless

12. Peeved

13. Considerate

14. Sad

15. Active

16. On Edge

17. Grouchy

18. Blue

19. Energetic

20. Panicky

21. Hopeless

22. Relaxed

23. Unworthy

24. Spiteful

25. Sympathetic

26. Uneasy

27. Restless

28. Unable to Concentrate

29. Fatigued

30. Helpful

31. Annoyed

$\begin{array}{lllll}0 & 1 & 2 & 3 & 4 \\ 0 & 1 & 2 & 3 & 4 \\ 0 & 1 & 2 & 3 & 4 \\ 0 & 1 & 2 & 3 & 4 \\ 0 & 1 & 2 & 3 & 4 \\ 0 & 1 & 2 & 3 & 4 \\ 0 & 1 & 2 & 3 & 4 \\ 0 & 1 & 2 & 3 & 4 \\ 0 & 1 & 2 & 3 & 4 \\ 0 & 1 & 2 & 3 & 4 \\ 0 & 1 & 2 & 3 & 4 \\ 0 & 1 & 2 & 3 & 4 \\ 0 & 1 & 2 & 3 & 4 \\ 0 & 1 & 2 & 3 & 4 \\ 0 & 1 & 2 & 3 & 4 \\ 0 & 1 & 2 & 3 & 4 \\ 0 & 1 & 2 & 3 & 4 \\ 0 & 1 & 2 & 3 & 4 \\ 0 & 1 & 2 & 3 & 4 \\ 0 & 1 & 2 & 3 & 4 \\ 0 & 1 & 2 & 3 & 4 \\ 0 & 1 & 2 & 3 & 4 \\ 0 & 1 & 2 & 3 & 4 \\ 0 & 1 & 2 & 3 & 4 \\ 0 & 1 & 2 & 3 & 4 \\ 0 & 1 & 2 & 3 & 4 \\ 0 & 1 & 2 & 3 & 4 \\ 0 & 1 & 2 & 3 & 4 \\ 0 & 1 & 2 & 3 & 4 \\ 0 & 1 & 2 & 3 & 4 \\ 0 & 1 & 2 & 3 & 4\end{array}$




$\begin{array}{llllll}\text { 32. Discouraged } & 0 & 1 & 2 & 3 & 4 \\ \text { 33. Resentful } & 0 & 1 & 2 & 3 & 4 \\ \text { 34. Nervous } & 0 & 1 & 2 & 3 & 4 \\ \text { 35. Lonely } & 0 & 1 & 2 & 3 & 4 \\ \text { 36. Miserable } & 0 & 1 & 2 & 3 & 4 \\ \text { 37. Muddled } & 0 & 1 & 2 & 3 & 4 \\ \text { 38. Cheerful } & 0 & 1 & 2 & 3 & 4 \\ \text { 39. Bitter } & 0 & 1 & 2 & 3 & 4 \\ \text { 40. Exhausted } & 0 & 1 & 2 & 3 & 4 \\ \text { 41. Anxious } & 0 & 1 & 2 & 3 & 4 \\ \text { 42. Ready to Fight } & 0 & 1 & 2 & 3 & 4 \\ \text { 43. Good Natured } & 0 & 1 & 2 & 3 & 4 \\ \text { 44. Gloomy } & 0 & 1 & 2 & 3 & 4 \\ \text { 45. Desperate } & 0 & 1 & 2 & 3 & 4 \\ \text { 46. Sluggish } & 0 & 1 & 2 & 3 & 4 \\ \text { 47. Rebellious } & 0 & 1 & 2 & 3 & 4 \\ \text { 48. Helpless } & 0 & 1 & 2 & 3 & 4 \\ \text { 49. Weary } & 0 & 1 & 2 & 3 & 4 \\ \text { 50. Bewildered } & 0 & 1 & 2 & 3 & 4 \\ \text { 51. Alert } & 0 & 1 & 2 & 3 & 4 \\ \text { 52. Deceived } & 0 & 1 & 2 & 3 & 4 \\ \text { 53. Furious } & 0 & 1 & 2 & 3 & 4 \\ \text { 54. Efficient } & 0 & 1 & 2 & 3 & 4 \\ \text { 55. Trusting } & 0 & 1 & 2 & 3 & 4 \\ \text { 56. Full of Pep } & 0 & 1 & 2 & 3 & 4 \\ \text { 57. Bed-Tempered } & 0 & 1 & 2 & 3 & 4 \\ \text { 58. Worthless } & 0 & 1 & 2 & 3 & 4 \\ \text { 59. Forgetful } & 0 & 1 & 2 & 3 & 4 \\ \text { 60. Carefree } & 0 & 1 & 2 & 3 & 4 \\ \text { 61. Terrified } & 0 & 1 & 2 & 3 & 4 \\ \text { 62. Guilty } & 0 & 1 & 2 & 3 & 4 \\ \text { 63. Vigorous } & 0 & 1 & 2 & 3 & 4 \\ \text { 64. Uncertain about things } & 0 & 1 & 2 & 3 & 4 \\ \text { 65. Bushed } & 0 & 1 & 2 & 3 & 4 \\ & 0 & 1 & 2 & 3 & 4\end{array}$




\section{Appendix B}

\section{NEO PI-R}

This questionnaire contains 240 statements. Please reach each item carefully and circle the one answer that best corresponds to your agreement or disagreement.

Circle "SD" if the statement is definitely false or if you strongly disagree

Circle "D" s the statement is mostly false or you disagree

Circle "N" if the statement is about equally true or false, if you cannot decide, or if you are neutral on the statement.

Circle " $\mathbf{A}$ " if the statement is mostly true or if you agree

Circle "SA" if the statement is definitely true or if you strongly agree.

There are no right or wrong answers, and you need not be an "exert" to complete this questionnaire. Describe the person honestly and state your opinions as accurately as possible. Answer every item.

1. She is not a worrier.

2. She really likes most people she meets.

3. She has a very active imagination.

4. She tends to be cynical and skeptical of others' intentions.

5. She is known for her prudence and common sense.

6. She often gets angry at the way people treat her.

7. She shies away from crowds of people.

8. Aesthetic and artistic concerns are not very important to her.

9. She is not crafty or sly.

10. She would rather keep her options open than plan everything in advance.

11. She rarely feels lonely or blue.

12. She is dominant, forceful, and assertive.

13. Without strong emotions, life would be uninteresting to her.

14. Some people think she is selfish and egotistical.

15. She tries to perform all the tasks assigned to her conscientiously.

16. In dealing with other people, she always dreads making a social blunder.

17. She has a leisurely style in work and play.

18. She is pretty set in her ways.

19. She would rather cooperate with others than compete with them

20. She is easy-going and lackadaisical.

21. She rarely overindulges in anything.

22. She often craves excitement.

23. She often enjoys playing with theories or abstract ideas.

24. She does not min bragging about her talents and accomplishments.

25. She is pretty good about pacing herself so as to get things done on time.

26. She often feels helpless and wants someone else to solve her problems.

27. She has never literally jumped for joy. 
28. She believes letting students hear controversial speakers can only confuse and mislead them.

29. She thinks political leaders need to be more aware of the human side of their policies.

30. Over the years she has done some pretty stupid things.

31. She is easily frightened.

32. She does not get much pleasure from chatting with people.

33. She tries to keep all her thoughts directed along realistic lines and avoids flights of fancy.

34. She believes that most people are basically well intentioned.

35. She does not take civic duties like voting very seriously.

36. She is n even-tempered person.

37. She likes to have a lot of people around her.

38. She is sometimes completely absorbed in music she is listening to.

39. If necessary, she is willing to manipulate people t get what she wants.

40. She keeps her belongings neat and clean.

41. Sometimes she feels completely worthless.

42. She sometimes fails to assert herself as much as she should.

43. She rarely experiences strong emotions.

44. She tries to be courteous to everyone she meets.

45. Sometimes she is not as dependable or reliable as she should be.

46. She seldom feels self-conscious when she is around people.

47. When she does things, she does the vigorously.

48. She thinks it is interesting to learn and develop new hobbies

49. She can be sarcastic and cutting when she needs to be.

50. She has a clear set of goals and works toward them in an orderly fashion.

51. She has trouble resisting her cravings.

52. She would not enjoy vacationing in Las Vegas.

53. She finds philosophical arguments boring.

54. She would rather not talk about herself and her achievements.

55. She wastes a lot of time before settling down to work.

56. She feels she is capable of coping with most of her problems.

57. She has sometimes experienced intense joy or ecstasy.

58. She believes that laws and social policies should change to reflect the needs of a changing world.

59. She is hardheaded and though minded in her attitudes.

60. She thinks thing through before coming to decision.

61. She rarely feels fearful or anxious.

62. She is a warm and friendly person.

63. She has an active fantasy life.

64. She believes that most people will take advantage of you if you let them.

65. She keeps herself informed and usually makes intelligent decisions.

66. She is hot-blooded and quick-tempered.

67. She usually prefers to do things alone.

68 . Watching ballet or modern dance bores her.

69. She could not bring herself to deceive anyone even if she wanted to. 
70. She is not a very methodical person.

71. She is seldom sad or depressed.

72. She has often been a leader of groups she has belonged to.

73. How she feels about things is important to her.

74. Some people think of her as cold and calculating.

75. She pays her debts promptly and in full.

76. At times she has been so ashamed she just wanted to hide.

77. Her work is likely to be slow but steady.

78. Once she finds the right way to do something, she sticks to it.

79. She hesitates to express her anger, even when it is justified.

80. When she starts a self-improvement program, she usually lets it slide after a few days,

81. She has little difficulty resisting temptation.

82. She has sometimes done things just for the "kicks" or "thrills".

83. She enjoys solving problems or puzzles.

84. She thinks she is better than most people.

85. She is a productive person who always gets the job done.

86. When she is under a great deal of stress, sometimes he feels like she is going to pieces.

87. She is not a cheerful optimist.

88. She believes we should look t our religious authorities or decision on moral issues.

89. She feels we can never do too much for the poor and elderly.

90. Occasionally she acts first and thinks later.

91. She often feels tense and jittery.

92. Many people think of her as somewhat cold and distant.

93. Se does not like to waster her time daydreaming.

94. She thinks most of the people she deals with are honest and trustworthy.

95. She often comes into situations without being fully prepared.

96. She is not considered a touchy or temperamental person.

97. She rarely feels the need for other people $\mathrm{f}$ she is by herself for long.

98. She is intrigued by the patterns she finds in art and nature

99. Se thinks being perfectly honest is a bad way of doing business.

100. She likes to keep everything in its place so she will know just where it is.

101. She has sometimes experienced a deep sense of guilt or sinfulness.

102. In meetings. She usually lets others do the talking.

103. She seldom pays too much attention to her feelings of the moment.

104. She generally tries to be thoughtful and considerate.

105. Sometimes she cheats when she plays solitaire.

106. It does not embarrass her too much if people ridicule and tease her.

107. She often feels as if she is bursting with energy

108. She often tries new and foreign foods.

109. If she does not like people, she will let them know it.

110. She works hard to accomplish her goals.

111. When she is having her favorite foods, she tends to eat too much.

112. She tends to avoid movies that are shocking or scary. 
113. She sometimes looses interest when people talk about very abstract, theoretical matters,

114. She tries to be humble.

115. She has trouble making herself down what she should.

116. She keeps a cool head in emergencies.

117. Sometimes she bubbles with happiness.

118. She believes that the different ideas of right and wrong that people in other societies have may be valid for them.

119. She has no sympathy for panhandlers.

120. She always considers the consequences before she takes action.

121. She is seldom apprehensive about the future.

122. She really enjoys talking to people

123. She enjoys concentrating on a fantasy or daydream and exploring all its possibilities, letting it grow and develop.

124. She is suspicious when someone does something nice for her.

125. She prides herself on her sound judgment.

126. She often gets disgusted with people she has to deal with.

127. She prefers jobs that let her work alone without being bothered by other people.

128. Poetry has little or no effect o her.

129. Show would hate to be thought of as a hypocrite.

130. She never seems o be able to get organized.

131. She tend to blame herself when anything goes wrong,

132. Other people often look to her to make decisions.

133. She experiences a wide range of emotions or feelings.

134. She is not known for her generosity.

135. When she makes a commitment, she can always be counted on to follow through.

136. She often feels inferior to others.

137. She is not as quick and lively as other people.

138. She prefers to spend her time in familiar surroundings.

139. When she has been insulted. She just tries to forgive and forget.

140. She does not feel like she is driven to get ahead.

141. She seldom gives in to her impulses.

142. She likes to be where the action is.

143. She enjoys working on "mind-twister" type puzzles.

144. She has a very high opinion of herself

145. Once she starts a project, she almost always finishes it.

146. It is often hard for her to make up her mind.

147. She is not especially light-hearted

148. She believes that loyalty to one's ideals and principles is more important than open-mindedness.

149. She believes that human needs should always take priority over economic considerations.

150. She often does things on the spur of the moment.

151. She often worries about things that might go wrong. 
152. She finds it was to smile ad be outgoing with strangers.

153. If she feels her mind starting to drift off into daydreams, she usually gets busy and starts concentrating on some work or activity instead.

154. Her first reaction is to trust people.

155. She does not seem to be completely successful at anything.

156. It tales a lot to let her mad.

157. She would rather vacation at a popular beach than in isolated cabin in the woods.

158. Certain kinds of music have an endless fascination for her.

159. Sometime she tricks people into doing what she wants.

160. She tends to be somewhat fastidious or exacting.

161. She has a low opinion of herself

162. She would rather go her own way then be a leader of others.

163. She seldom notices the moods or feelings that different environments produce.

164. Most people she knows like her.

165. She adheres strictly to her ethical principles.

166. She feels comfortable in the presence of her bosses or other authorities.

167. She usually seems to be in a hurry.

168. Sometimes she makes changes around the house just to try something different.

169. If someone starts a fight, she is ready to fight back.

170. She strives to achieve all she can.

171. She sometimes eats herself sick.

172. She loves the excitement of roller coasters.

173. She has little interest in speculating on the nature of the universe or the human condition.

174. She feels that she is no better than others, no matter what their condition.

175. When a project gets too difficult, she is inclined t start a new one.

176. She can handle herself pretty well in a crisis.

177. She is a cheerful, high-spirited person.

178. She considers herself broad-minded and tolerant of other people's lifestyles.

179. She believes all human beings are worthy of respect.

180. She rarely makes hasty decisions.

181. She has fewer fears than most people.

182. She has strong emotional attachments to her friends.

183. As a child she rarely enjoyed dames of make believe.

184. She tends o assume the best about people.

185. She is a very competent person.

186. At times she has felt bitter and resentful.

187. Social gatherings are usually boring to her.

188. Sometimes when she is reading poetry or looking at a work of art, she feels a chill or wave of excitement.

189. At times she bullies or flatters people into doing what she wants them to.

190. She is not compulsive about cleaning. 
191. Sometimes things look pretty bleak and hopeless to her.

192. In conversations, she tends to do most of the talking.

193. She finds it easy to empathize- to feel herself what others are feeling.

194. She thinks of herself as a charitable person.

195. She tries to do jobs carefully, so they won't have to be done again.

196. If she has said or done the wrong thing to someone, she can hardly bear to face him or her again.

197. Her life is fast-paced.

198. On a vacation, she prefers going to a tried and true spot.

199. She is hardheaded and stubborn.

200. She strives for excellence in everything she does.

201. Sometimes she does things on impulse that she later regrets.

202. She is attracted to bright colors and flashy styles.

203. She has a lot of intellectual curiosity.

204. She would rather praise others than be praised herself.

205. There are so many little jobs that need to be done that she sometimes just ignored them all.

206. When everything seems to be going wrong, she can still make good decision.

207. She rarely used words like "fantastic!" or "sensational!" to describe her experiences/

208. She thinks that if people do not know what they believe in by the time they are 25 , there is something wrong with them.

209. She has sympathy for others less fortunate than her.

210. She plans ahead carefully when she goes on a trip.

211. Frightening thoughts sometimes come into her head.

212. She takes a personal interest in the people she works with.

213. She would have difficulty just letting her mind wander without control or guidance.

214. She has a good deal of faith in human nature.

215. She is efficient at her work.

216. Even minor annoyances can be frustrating to her.

217. She enjoys parties with lots of people.

218. She enjoys reading poetry that emphasizes feelings and images more than story lines.

219. She prides herself on her own shrewdness in handling people.

220. She spends a lot of time looking for things she has misplaced.

221. Too often, when things go wrong, she gets discouraged and feels like giving up.

222. He does not find it easy $t$ take charge of a situation.

223. Odd things-like certain scents or the names of distant places-can evoke strong moods in her.

224. She goes out of her way to help others if she can.

225. She would really have to be sick before she would miss a day of work.

226. When people she knows do foolish things, she gets embarrassed for them.

227. She is a very active person. 
228. She follows the same route when she goes someplace.

229. She often gets into arguments with her family and co-workers.

230. She is something of a "workaholic".

231. She is always able to keep her feelings under control.

232. She likes being part of the crowd at sporting events.

233. She has a wide range of intellectual interests.

234. She thinks she is a superior person.

235. She has a lot of self-discipline.

236. She is pretty stable emotionally.

237. She laughs easily.

238. She believes that the "new morality" of permissiveness is no morality at all.

239. She would rather be known as "merciful" than as "just".

240. She thinks twice before she answers a question. 


\section{Appendix C}

\begin{tabular}{|c|c|c|}
\hline \multicolumn{3}{|c|}{ Multi-Dimensional Emotional Empathy Scale (Caruso \& Mayer, 1998). } \\
\hline 1. & I feel like crying when watching a sad movie. & 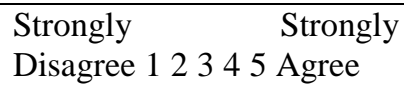 \\
\hline 2. & Certain pieces of music can really move me. & 12345 \\
\hline 3. & Seeing a hurt animal by the side of the road is very upsetting. & 12345 \\
\hline 4. & I don't give others' feelings much thought. & 123345 \\
\hline 5. & It makes me happy when I see people being nice to each other. & 12345 \\
\hline 6. & The suffering of others deeply disturbs me. & 12345 \\
\hline 7. & I always try to tune in to the feelings of those around me. & 12345 \\
\hline 8. & I get very upset when I see a young child who is being treated meanly. & 123345 \\
\hline 9. & Too much is made of the suffering of pets or animals. & 12345 \\
\hline 10. & If someone is upset I get upset, too. & 12345 \\
\hline 11. & When I'm with other people who are laughing I join in. & 123345 \\
\hline 12. & It makes me mad to see someone treated unjustly. & 12345 \\
\hline 13. & I rarely take notice when people treat each other warmly. & 12345 \\
\hline 14. & I feel happy when I see people laughing and enjoying themselves. & 12345 \\
\hline 15. & It's easy for me to get carried away by other people's emotions. & 12345 \\
\hline 16. & My feelings are my own and don't reflect how others feel. & 12345 \\
\hline 17. & If a crowd gets excited about something so do I. & 123345 \\
\hline 18. & I feel good when I help someone out or do something nice for someone. & 12345 \\
\hline 19. & I feel deeply for others. & 123345 \\
\hline 20. & I don't cry easily. & 122345 \\
\hline 21. & I feel other people's pain. & 12345 \\
\hline 22. & Seeing other people smile makes me smile. & 122345 \\
\hline 23. & Being around happy people makes me feel happy, too. & 122345 \\
\hline 24. & TV or news stories about injured or sick children greatly upset me. & 12345 \\
\hline 25. & I cry at sad parts of the books I read. & 122345 \\
\hline 26. & Being around people who are depressed brings my mood down. & 123345 \\
\hline 27. & I find it annoying when people cry in public. & 12345 \\
\hline 28. & It hurts to see another person in pain. & 122345 \\
\hline 29. & I get a warm feeling for someone if I see them helping another person. & 122345 \\
\hline 30. & I feel other people's joy. & 12345 \\
\hline
\end{tabular}




\section{Appendix D}

\section{PTSD Checklist Civilian Version (PTSD-C)}

INSTRUCTIONS: Below is a list of problems and complaints that people sometimes have in response to stressful experiences. Please read each one carefully, put an X in the box to indicate how much you have been bothered by that problem RIGHT NOW.

1. Repeated, disturbing memories, thoughts, or images of a stressful experience?

1. Not at all 2. A little bit 3. Moderately 4. Quite a bit 5. Extremely

2. Repeated, disturbing dreams of a stressful experience?

1. Not at all 2. A little bit 3. Moderately 4. Quite a bit 5. Extremely

3. Suddenly acting or feeling as if a stressful experience were happening again (as if you were reliving it)?

1. Not at all 2. A little bit 3. Moderately 4. Quite a bit 5. Extremely

4. Feeling very upset when something reminded you of a stressful experience?

1. Not at all 2. A little bit 3. Moderately 4. Quite a bit 5. Extremely

5. Having physical reactions (e.g., heart pounding, trouble breathing, sweating) when something reminded you of a stressful experience?

1. Not at all 2. A little bit 3. Moderately 4. Quite a bit 5. Extremely

6. Avoiding thinking about or talking about a stressful experience or avoiding having feelings related to it?

1. Not at all 2. A little bit 3. Moderately 4. Quite a bit 5. Extremely

7. Avoiding activities or situations because they reminded you of a stressful experience?

1. Not at all 2. A little bit 3. Moderately 4. Quite a bit 5. Extremely

8. Trouble remembering important parts of a stressful experience?

1. Not at all 2. A little bit 3. Moderately 4. Quite a bit 5. Extremely

9. Loss of interest in activities that you used to enjoy? 
1. Not at all 2. A little bit 3. Moderately 4. Quite a bit 5. Extremely

10. Feeling distant or cut off from other people?

1. Not at all 2. A little bit 3. Moderately 4. Quite a bit 5. Extremely

11. Feeling emotionally numb or being unable to have loving feelings for those close to you?

1. Not at all 2. A little bit 3. Moderately 4. Quite a bit 5. Extremely

12. Feeling as if your future will somehow be cut short?

1. Not at all 2. A little bit 3. Moderately 4. Quite a bit 5. Extremely

13. Trouble falling or staying asleep?

1. Not at all 2. A little bit 3. Moderately 4. Quite a bit 5. Extremely

14. Feeling irritable or having angry outbursts?

1. Not at all 2. A little bit 3. Moderately 4. Quite a bit 5. Extremely

15. Having difficulty concentrating?

1. Not at all 2. A little bit 3. Moderately 4. Quite a bit 5. Extremely

16. Being "super-alert" or watchful or on guard?

1. Not at all 2. A little bit 3. Moderately 4. Quite a bit 5. Extremely

17. Feeling jumpy or easily startled?

1. Not at all 2. A little bit 3. Moderately 4. Quite a bit 5. Extremely 
